\title{
Seasonal Mixed Layer Heat Balance of the Southwestern Tropical Indian Ocean*
}

\author{
GREGORY R. FOLTZ \\ Joint Institute for the Study of the Atmosphere and Ocean, University of Washington, Seattle, Washington \\ JÉRÔME VIALARD \\ IRD/Laboratoire d'Océanographie: Expérimentation et Approches Numériques, Paris, France \\ B. PRAVEen Kumar \\ Physical Oceanography Division, National Institute of Oceanography, Dona Paula, Goa, India
}

Michael J. MCPHADEN

NOAA/Pacific Marine Environmental Laboratory, Seattle, Washington

(Manuscript received 29 May 2009, in final form 26 August 2009)

\begin{abstract}
Sea surface temperature (SST) in the southwestern tropical Indian Ocean exerts a significant influence on global climate through its influence on the Indian summer monsoon and Northern Hemisphere atmospheric circulation. In this study, measurements from a long-term moored buoy are used in conjunction with satellite, in situ, and atmospheric reanalysis datasets to analyze the seasonal mixed layer heat balance in the thermocline ridge region of the southwestern tropical Indian Ocean. This region is characterized by a shallow mean thermocline $\left(90 \mathrm{~m}\right.$, as measured by the $20^{\circ} \mathrm{C}$ isotherm) and pronounced seasonal cycles of Ekman pumping and SST (seasonal ranges of -0.1 to $0.6 \mathrm{~m}^{\text {day }}{ }^{-1}$ and $26^{\circ}-29.5^{\circ} \mathrm{C}$, respectively). It is found that surface heat fluxes and horizontal heat advection contribute significantly to the seasonal cycle of mixed layer heat storage. The net surface heat flux tends to warm the mixed layer throughout the year and is strongest during boreal fall and winter, when surface shortwave radiation is highest and latent heat loss is weakest. Horizontal heat advection provides warming during boreal summer and fall, when southwestward surface currents and horizontal SST gradients are strongest, and is close to zero during the remainder of the year. Vertical turbulent mixing, estimated as a residual in the heat balance, also undergoes a significant seasonal cycle. Cooling from this term is strongest in boreal summer, when surface wind and buoyancy forcing are strongest, the thermocline ridge is shallow $(<90 \mathrm{~m})$, and the mixed layer is deepening. These empirical results provide a framework for addressing intraseasonal and interannual climate variations, which are dynamically linked to the seasonal cycle, in the southwestern tropical Indian Ocean. They also provide a quantitative basis for assessing the accuracy of numerical ocean model simulations in the region.
\end{abstract}

\section{Introduction}

The southwestern tropical Indian Ocean is characterized by a pronounced thermocline ridge known as the

* Pacific Marine Environmental Laboratory Contribution Number 3443, Joint Institute for the Study of the Atmosphere and Ocean Contribution Number 1767, and National Institute of Oceanography Contribution Number 4673.

Corresponding author address: Gregory R. Foltz, 7600 Sand Point Way NE, Seattle, WA 98133.

E-mail: gregory.foltz@noaa.gov
Seychelles-Chagos thermocline ridge (SCTR; Fig. 1). The SCTR is maintained primarily by Ekman pumping associated with a northward weakening of the southeasterly trade winds. Sea surface temperature (SST) remains warm in the SCTR region $\left(>26^{\circ} \mathrm{C}\right.$ throughout the year and $28^{\circ} \mathrm{C}$ in the annual mean), despite a shallow thermocline and annual-mean upwelling. These conditions are typical of those found in other tropical convergence zones. For example, the thermocline depth and SST in the SCTR region are similar to those found in the Atlantic and central tropical Pacific intertropical convergence zones $\left(2^{\circ}-8^{\circ} \mathrm{N}\right.$, $20^{\circ}-45^{\circ} \mathrm{W}$ and $5^{\circ}-10^{\circ} \mathrm{N}, 120^{\circ}-160^{\circ} \mathrm{W}$, respectively). 

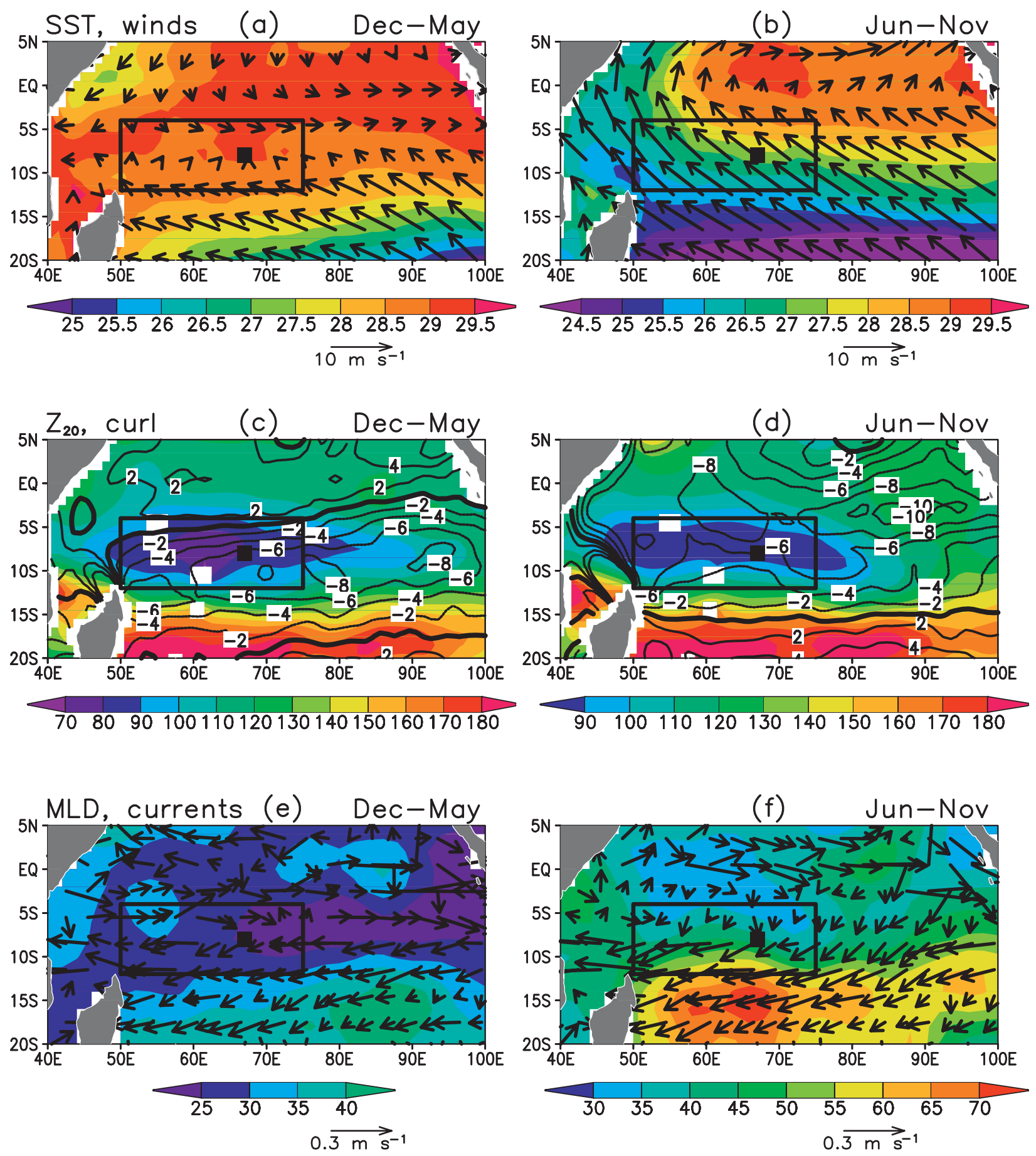

FIG. 1. Climatological (2000-07) SST (shaded; ${ }^{\circ} \mathrm{C}$ ) and surface wind vectors during (a) December-May and (b) June-November. The box encloses the SCTR region, and the solid black square is the position of the $8^{\circ} \mathrm{S}, 67^{\circ} \mathrm{E}$ RAMA mooring. (c),(d) As in (a),(b), but for thermocline depth as inferred from the $20^{\circ} \mathrm{C}$ isotherm (shaded; $\mathrm{m}$ ) and wind stress curl (contours; $10^{-5} \mathrm{~N} \mathrm{~m}^{-3}$ ). (e),(f) As in (a),(b), but for MLD (shaded; $\mathrm{m}$ ) and surface current vectors.

Because of high mean SSTs in the SCTR region, small perturbations can exert a strong influence on weather and climate on the surrounding continents. Interannual SST anomalies in the SCTR region affect rainfall in East
Africa (Goddard and Graham 1999; Black et al. 2003; Ummenhofer et al. 2009), the onset and strength of the Indian summer monsoon (Joseph et al. 1994; Vecchi and Harrison 2004; Annamalai et al. 2005; Izumo et al. 
2008), and ENSO teleconnections to the North Pacific (Annamalai et al. 2007). There are also strong intraseasonal fluctuations of SST in the SCTR region that are associated with the eastward-propagating Madden-Julian oscillation (e.g., Duvel and Vialard 2007). Ocean dynamics seem to be responsible for most of the SST variability on interannual time scales (Murtugudde and Busalacchi 1999; Xie et al. 2002), whereas surface fluxes and entrainment appear to contribute significantly to intraseasonal SST variability (Vecchi and Harrison 2001; Saji et al. 2006; Duvel and Vialard 2007; Han et al. 2007; Vinayachandran and Saji 2008; Vialard et al. 2008).

Interannual and intraseasonal SST variability in the SCTR region is superimposed on a pronounced seasonal cycle (Figs. 1a,b). Several previous studies have addressed the seasonal cycle in the SCTR region. Hermes and Reason (2008) used a regional ocean model to investigate the seasonal cycle in the SCTR region and found that the net surface heat flux is balanced to a large extent by the sum of horizontal convergence and vertical diffusion. In their model, the upper-ocean heat content in the SCTR region is a small residual between these two larger terms and is characterized by a strong semiannual cycle. Using an ocean general circulation model, Yokoi et al. (2008) found a pronounced semiannual variation of upper-ocean heat content (averaged from the surface to $100 \mathrm{~m}$ ), which is in agreement with Hermes and Reason (2008). In their model, the seasonal cycle of heat content was driven mainly by a strong semiannual cycle of Ekman pumping, with weaker and out-of-phase contributions from horizontal advection and the net surface heat flux. They showed that the semiannual cycle of Ekman pumping is due to the interference between the curl and beta terms. Zhou et al. (2008) analyzed the mixed layer temperature balance in the SCTR region from an ocean general circulation model. During boreal summer, they found that there is strong warming from horizontal advection that balances cooling from entrainment. As a result, the seasonal cycle of SST is driven primarily by the net surface heat flux. They also show that the seasonal cycle of Indonesian Throughflow affects the vertical stratification and hence the seasonality of the entrainment heat flux.

The aforementioned studies suggest that surface heat fluxes, horizontal advection, and entrainment play important roles in the upper-ocean heat balance of the SCTR region. However, these studies are inconclusive regarding the causes of the seasonal cycle of SST. For example, Hermes and Reason (2008) and Yokoi et al. (2008) investigated seasonal variations in upper-ocean heat content, but they did not explicitly address the causes of the strong seasonal cycle of SST. Zhou et al. (2008) analyzed the mixed layer temperature balance, but for a limited region $\left(6^{\circ} \mathrm{S}-7^{\circ} \mathrm{S}, 63^{\circ}-73^{\circ} \mathrm{E}\right)$. All three studies relied on output from numerical ocean models. In this study, we analyze the mixed layer heat budget in the SCTR region from a combination of satellite and in situ datasets and simple one-dimensional diagnostic models, expanding on previous modeling studies.

\section{Data}

We use a combination of satellite and in situ datasets to analyze the mixed layer heat budget in the southwestern tropical Indian Ocean. Satellite and Argo data are used to examine the heat budget in the SCTR region during 200008. Measurements from a buoy of the Research Moored Array for African-Asian-Australian Monsoon Analysis and Prediction (RAMA; McPhaden et al. 2009) at $8^{\circ} \mathrm{S}$, $67^{\circ} \mathrm{E}$ complement the larger-scale analysis, providing direct measurements at a single location during 2007-08.

\section{a. Satellite and Argo}

SST and rainfall are available from the Tropical Rainfall Measuring Mission (TRMM) Microwave/Imager (TMI) on a $0.5^{\circ} \times 0.5^{\circ} \times 3$-day grid from December 1997 to the present. We also use a combined TMI-Advanced Microwave Scanning Radiometer for Earth Observing System (AMSR-E) SST dataset on the same spatial grid for the time period of June 2002-present. Surface wind velocity was obtained from the SeaWinds scatterometer onboard the Quick Scatterometer (QuikSCAT) satellite on a $0.25^{\circ} \times 0.25^{\circ} \times 3$-day grid beginning in July 1999 . Monthly-mean estimates of near-surface chlorophyll-a (chl-a) concentration from the Sea-Viewing Wide Fieldof-View Sensor (SeaWiFS) onboard the SeaStar satellite are used to calculate penetrative shortwave radiation (SWR). These data are available on a $0.08^{\circ} \times 0.08^{\circ}$ grid for 1997-present.

The Coriolis Centre at the French Institute for Exploitation of the Sea (IFREMER) produces weekly threedimensional analyses of temperature, salinity, and density based on Argo and other available mooring, XBT, and CTD data. The analyses are produced using an optimal interpolation scheme with climatology used as a background (Gaillard et al.2009). The data are available on a global grid with $\sim 0.5^{\circ}$ horizontal resolution and vertical resolution of 5-20 m in the upper $300 \mathrm{~m}$. We use the temperature, salinity, and density analyses computed weekly to compute the mixed layer depth (MLD), isothermal layer depth (ILD), depth of the $20^{\circ} \mathrm{C}$ isotherm, and temperature jump at the base of the mixed layer (these datasets are referred to as the "Coriolis" MLD, ILD, etc.). The MLD is computed using the criterion of a $0.15 \mathrm{~kg} \mathrm{~m}^{-3}$ density increase from the density at a depth of $5 \mathrm{~m}$. The ILD is calculated using the 
temperature equivalent of a $0.15 \mathrm{~kg} \mathrm{~m}^{-3}$ increase from a depth of $5 \mathrm{~m}$. The temperature jump at the base of the mixed layer $\Delta T$ is computed as the difference between the mean mixed layer temperature and the temperature $10 \mathrm{~m}$ below the base of the mixed layer. For heat budget sensitivity tests, we also use a monthly gridded MLD product that is based on individual Argo temperature and salinity profiles (C. de Boyer Montégut 2009, personal communication). In this dataset, the MLD is defined using the criterion of a $0.03 \mathrm{~kg} \mathrm{~m}^{-3}$ density increase from a depth of $10 \mathrm{~m}$. This smaller criterion was found to be optimal for estimating MLD from individual profiles (de Boyer Montégut et al. 2004).

We use two different estimates of horizontal velocity. The first calculates horizontal velocity averaged in the upper $30 \mathrm{~m}$ from the Ocean Surface Current AnalysisReal time (OSCAR; Bonjean and Lagerloef 2002). This method uses satellite sea level, wind stress, and SST, together with a diagnostic model, to calculate velocity on a $1^{\circ} \times 1^{\circ} \times 5$-day grid for the time period 1993-2006. The second uses near-surface velocity from satellitetracked drifting buoys and is available as a monthlymean climatology on a $1^{\circ} \times 1^{\circ}$ grid (Lumpkin and Garzoli 2005). The OSCAR product has the advantage of more complete spatial and temporal coverage than the drifter-based climatology, because it uses satellite measurements, but it has the disadvantage of not being constrained by direct velocity observations.

Two different net surface heat flux products are used in this study. For the first product (Flux QuikSCAT $_{\text {), latent }}$ heat flux (LHF) and sensible heat flux (SHF) are calculated with version 3.0 of the Coupled Ocean-Atmosphere Response Experiment (COARE) bulk flux algorithm (Fairall et al. 2003) using daily QuikSCAT wind speed (WS), TMI SST, and National Centers for Environmental Prediction-National Center for Atmospheric Research (NCEP-NCAR) reanalysis surface air temperature (AT) and specific humidity (Kalnay et al. 1996). Air temperature and specific humidity were corrected for systematic biases using February 2007-November 2008 daily measurements from the RAMA mooring at $8^{\circ} \mathrm{S}, 67^{\circ} \mathrm{E}$ (described in section 2b). The correction was performed by subtracting the mean difference (February 2007November 2008) between the collocated mooring and NCEP humidity (air temperature) at $8^{\circ} \mathrm{S}, 67^{\circ} \mathrm{E}$ from the NCEP humidity (air temperature) at each grid point. The surface shortwave radiation (SWR) product from Zhang et al. (2004) is available during 1983-2006 on a $2.5^{\circ} \times 2.5^{\circ}$ daily grid. To obtain a SWR product until the end of 2008, we regressed interannual anomalies of NOAA outgoing longwave radiation (Liebmann and Smith 1996) onto the Zhang et al. SWR anomalies, then added the resultant SWR anomalies to the seasonal cycle of shortwave radiation product from Zhang et al. (2004). The resulting SWR product is very similar to the original product from Zhang et al. (2004), with a correlation (RMS difference) of $0.9\left(12 \mathrm{~W} \mathrm{~m}^{-2}\right)$ for weekly values over the SCTR region. The total net surface SWR was obtained assuming an albedo of $6 \%$. We calculate net longwave radiation emission (LWR) from the Clark et al. (1974) bulk formula using daily NCEP-NCAR reanalysis air temperature and humidity, TMI SST, and the SWR product described earlier, following the methodology of Foltz and McPhaden (2005).

The second net surface heat flux product (Flux OAFlux $_{\text {) }}$ consists of latent and sensible heat fluxes from the objectively analyzed air-sea heat fluxes (OAFlux; Yu and Weller 2007). This dataset is available on a $1^{\circ} \times 1^{\circ}$ grid for the time period 1958-2006. Surface shortwave radiation is obtained from Zhang et al. (2004). Surface longwave radiation is obtained from the NCEP/Department of Energy (DOE) Reanalysis 2 (NCEP-2; Kanamitsu et al. 2002) on a $2^{\circ} \times 2^{\circ} \times$ daily grid for the time period 1979-2006. Each of these datasets is available at a daily resolution.

We use the Flux QuikSCAT $_{\text {product along with the Coriolis }}$ MLD, mixed layer temperature, and $\Delta T$; the OSCAR currents; and the TMI SST to calculate the terms in the mixed layer heat budget during January 2000 through September 2008, when all datasets are available. The methodology used to compute the heat budget is described in section 3 . The Flux OAflux $_{\text {product is used }}$ along with the drifter climatology, the de Boyer Montégut MLD, and the other datasets described in this section to assess the sensitivity of the mixed layer heat balance to different choices of surface flux, velocity, and MLD products [the sensitivity tests are discussed in detail in section $4 \mathrm{c}(1)]$. The combined TMI-AMSR-E SST is used for the heat budget analysis at the mooring location (described in section 3b), and the TMI precipitation and QuikSCAT winds are used along with Flux $_{\text {QuikSCAT }}$ to calculate surface buoyancy and wind stress forcing in the SCTR region (section 4).

\section{b. RAMA mooring}

To complement the global datasets described in section 2a, we use measurements from a RAMA mooring located at $8^{\circ} \mathrm{S}, 67^{\circ} \mathrm{E}$. This mooring was first deployed in January 2007 during the Cirene cruise (Vialard et al. 2009) and was serviced in August 2009 by R/V Marion Dufresne. Measurements, which began in mid-January 2007 and continued through the present, include subsurface temperature, salinity, and velocity, as well as air temperature, relative humidity $(\mathrm{RH})$, wind velocity, shortwave radiation, and precipitation. Ocean temperature is measured at 1 (i.e., bulk SST), 5, 10, 20, 40, 60, 80, 100, 120, 140, 300, and $500 \mathrm{~m}$, whereas salinity is measured at $1,10,20,40$, 

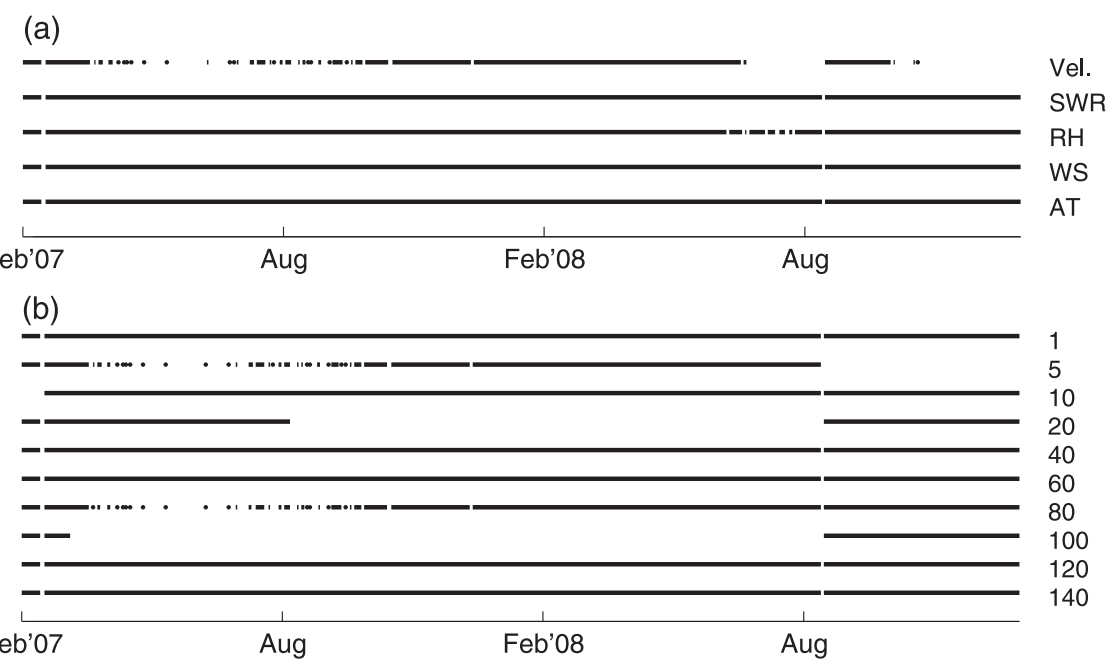

(c)

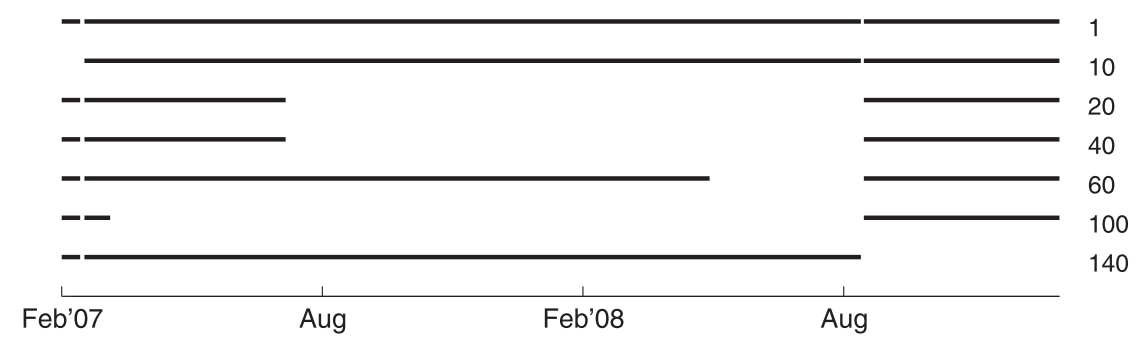

FIG. 2. (a) Availability of daily horizontal velocity, SWR, RH, WS, and AT from the $8^{\circ} \mathrm{S}$, $67^{\circ} \mathrm{E}$ mooring. Availability of subsurface (b) temperature and (c) salinity at depths between 1 and $140 \mathrm{~m}$.

60,100 , and $140 \mathrm{~m}$. Velocity is measured at a depth of $10 \mathrm{~m}$, and meteorological measurements are made at heights of 3-4 m above mean sea level.

We use daily averaged data for the time period February 2007-August 2008. The combination of instrument failure and vandalism resulted in gaps in some of the time series (Fig. 2). We have used vertical linear interpolation to replace the gaps in the subsurface temperature and salinity time series. The longest gaps for temperature are at depths of 20 and $100 \mathrm{~m}$ and for salinity are at 20, 40, and $100 \mathrm{~m}$. The gaps at $100 \mathrm{~m}$ do not affect the calculations in our analyses, because the MLD is always $<60 \mathrm{~m}$. We have subsampled temperature and salinity profiles from the mooring during periods when all data are available in the upper $80 \mathrm{~m}$ (February-July 2007 and September-November 2008) and found that the interpolated $20-\mathrm{m}$ temperature is on average $0.4^{\circ} \mathrm{C}$ lower than the actual 20-m temperature, and the RMS difference between the interpolated and actual 20-m temperature is $0.5^{\circ} \mathrm{C}$. For 20 -m salinity, the mean bias (RMS difference) is 0.03 (0.10); for 40-m salinity, the bias (RMS difference) is $0.01(0.16)$. These interpolation errors contribute to errors in daily MLD of $\pm 9 \mathrm{~m}$, as discussed in the appendix. Subsurface velocity measurements are unavailable during April-July 2007 and July-August 2008. We have filled the data gaps with OSCAR 5-day currents interpolated to a daily resolution after correcting for the record length mean bias (OSCAR westward and southward currents are 4 and $3 \mathrm{~cm} \mathrm{~s}^{-1}$ larger than mooring currents). The RMS difference between 5-day-averaged mooring and OSCAR currents is $7 \mathrm{~cm} \mathrm{~s}^{-1}\left(6 \mathrm{~cm} \mathrm{~s}^{-1}\right)$ for the zonal (meridional) component. The correlation between 5-day OSCAR and buoy currents is 0.9 for each component.

\section{Methodology}

To address the seasonal mixed layer heat balance in the SCTR region, we consider a simplified version of the mixed layer heat balance (e.g., Moisan and Niiler 1998),

$$
\rho c_{p} h \frac{\partial T}{\partial t}=q_{0}-\rho c_{p} h \mathbf{v} \cdot \nabla T+q_{-h}+\epsilon
$$

The terms in (1) represent, from left to right, mixed layer heat storage rate, surface heat flux corrected for the 
penetration of shortwave radiation through the base of the mixed layer, horizontal mixed layer heat advection, and the combination of entrainment and vertical turbulent diffusion at the base of the mixed layer. Entrainment implicitly contains the portion of vertical advection that is linked to water mass transformation. Errors in the estimation of the terms in (1), as well as neglected physical processes, are represented by $\epsilon$. Here, $h$ is the mixed layer depth and $T$ and $\mathbf{v}$ are temperature and velocity, respectively, vertically averaged from the surface to a depth of $-h$. We diagnose the heat budget in the SCTR region $\left(50^{\circ}-75^{\circ} \mathrm{E}, 5^{\circ} \mathrm{S}-12^{\circ} \mathrm{S}\right)$ using a combination of satellite, atmospheric reanalysis, and Argo data and compare to the budget at the $8^{\circ} \mathrm{S}, 67^{\circ} \mathrm{E}$ RAMA mooring location. The bounds for the SCTR region were chosen to encompass the region with a local minimum in thermocline depth $(<90 \mathrm{~m})$ and are consistent with those used in previous studies of SCTR variability (Xie et al. 2002; Hermes and Reason 2008; Yokoi et al. 2008).

\section{a. Satellite/Argo analysis}

We use weekly estimates of $h$ and $\partial T / \partial t$ from the Coriolis analysis to calculate mixed layer heat storage rate in the SCTR region. We regrid the TMI SST to a $1^{\circ}$ resolution and calculate daily SST gradients as centered differences over a distance of $2^{\circ}$. The daily TMI SST gradients and 5-day OSCAR currents are averaged to weekly means and are used along with $h$ to calculate horizontal mixed layer heat advection. The weekly heat storage rate and horizontal advection terms are then averaged to monthly means.

We use the monthly-mean Flux ${ }_{\text {QuikSCAT }}$ dataset described in section 2a to calculate the surface heat flux $q_{0}$, which consists of latent and sensible heat loss, absorbed shortwave radiation, and net longwave radiation emission. Following Morel and Antoine (1994) and Sweeney et al. (2005), we model the amount of SWR penetrating through the base of the mixed layer as $q_{\text {pen }}=$ $0.47 q_{\mathrm{sfc}}\left(V_{1} e^{-h / d_{1}}+V_{2} e^{-h / d_{2}}\right)$, where $q_{\mathrm{sfc}}$ is the surface shortwave radiation, $d_{1}$ and $d_{2}$ are the $e$-folding depths of the long visible $\left(d_{1}\right)$ and short visible and ultraviolet $\left(d_{2}\right)$ wavelengths, and $h$ is the depth of the mixed layer in meters. The parameters $V_{1}, V_{2}, d_{1}$, and $d_{2}$ are estimated using the monthly-mean seasonal cycle of SeaWiFS chl-a concentration interpolated to a daily resolution, following Sweeney et al. (2005). In this study, we use the convention that surface heat fluxes are positive when they tend to heat the mixed layer.

We have neglected a term in (1) that is proportional to the horizontal divergence of the vertically averaged temperature-velocity covariance [see Eq. (A19) of Moisan and Niiler 1998]. We found that this term is insignificant in comparison to the other terms in (1), based on monthly- mean data for 2000-04 from the Simple Ocean Data Assimilation (SODA; Carton et al. 2000). The covariance term is zero in the annual mean averaged over the SCTR region, and the magnitude of each monthly value is $<4 \mathrm{~W} \mathrm{~m}^{-2}$. The weakness of this term in comparison to the other terms in the heat balance is consistent with the results of Swenson and Hansen (1999) in the equatorial Pacific. We are also unable to reliably estimate $q_{-h}$ directly and therefore estimate this term as the difference between the observed mixed layer heat storage rate and the sum of the net surface heat flux and horizontal advection.

\section{b. RAMA mooring analysis}

In addition to the large-scale heat budget analysis for the SCTR region, we consider the heat balance at the $8^{\circ} \mathrm{S}, 67^{\circ} \mathrm{E}$ RAMA mooring location. The main advantages of using the mooring data compared to Argo and satellite datasets are the smaller errors associated with the mooring surface flux measurements and the higher temporal resolution of the mooring data. Mixed layer depth and vertically averaged mixed layer temperature are calculated from buoy subsurface temperature and salinity using the criterion of a $0.15 \mathrm{~kg} \mathrm{~m}^{-3}$ density increase from a depth of $1 \mathrm{~m}$ for $h$. We use buoy horizontal currents at $10 \mathrm{~m}$ along with TMI SST gradients, calculated as centered differences over a distance of $2^{\circ}$, to calculate horizontal mixed layer heat advection.

Latent and sensible heat fluxes are calculated from version 3.0 of the COARE bulk flux algorithm (Fairall et al. 2003) with daily buoy estimates of SST, air temperature, relative humidity, and wind speed. Surface SWR is available directly from the moorings, assuming an albedo of $6 \%$. The penetrative component of SWR is calculated using the method described in section $3 \mathrm{a}$. We calculate net LWR with buoy air temperature, relative humidity, SST, and SWR using the Clark et al. (1974) algorithm. The $q_{-h}$ term is estimated as the residual in the heat balance.

\section{Results}

In this section, we begin by examining the mean seasonal cycle in the southwestern tropical Indian Ocean. We then analyze the mixed layer heat balance in the SCTR region and at the $8^{\circ} \mathrm{S}, 67^{\circ} \mathrm{E}$ RAMA mooring location.

\section{a. Seasonal cycle}

The southwestern tropical Indian Ocean is characterized by a strong seasonal cycle of SST and surface winds. During boreal winter and spring, a pool of warm SSTs 

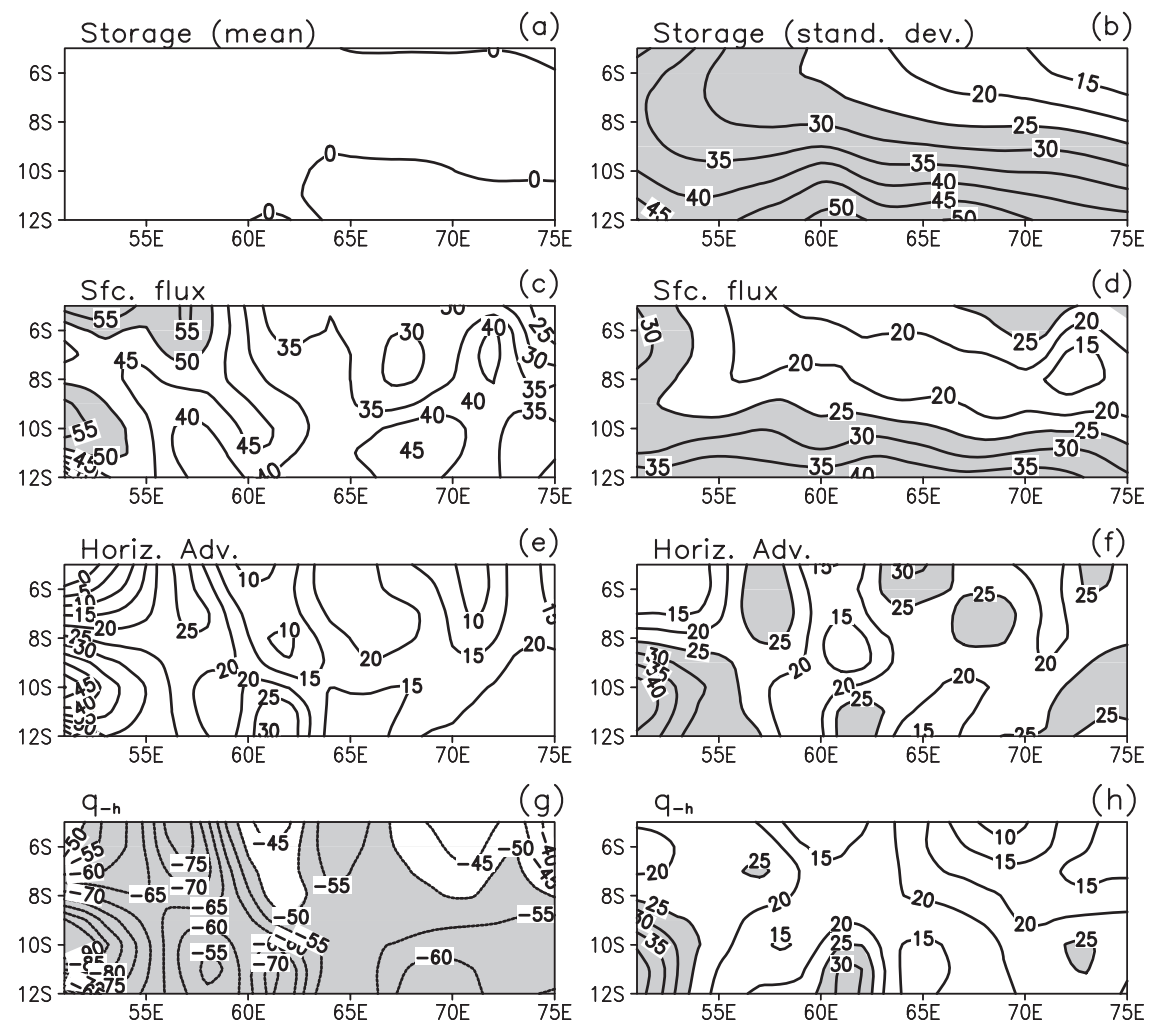

FIG. 3. Annual-mean (2000-08) (a) mixed layer heat storage rate, (c) net surface heat flux, (e) horizontal mixed layer heat advection, and ( $\mathrm{g}$ ) vertical heat flux at the base of the mixed layer in the SCTR region. Absolute values $>50 \mathrm{~W} \mathrm{~m}^{-2}$ are shaded. (b),(d),(f),(h) As in (a),(c),(e),(g) but for the standard deviation of the monthly-mean seasonal cycle. Values $>25 \mathrm{~W} \mathrm{~m}^{-2}$ are shaded.

extends southwestward from Indonesia to the African coast. SST exceeds $28^{\circ} \mathrm{C}$ throughout the SCTR region during these seasons (Fig. 1a). The southeasterly trade winds converge over the warmest SST between the equator and $10^{\circ} \mathrm{S}$. Cyclonic (i.e., negative) wind stress curl and associated Ekman pumping maintain a shallow thermocline $(<100 \mathrm{~m})$ throughout the SCTR region in boreal winter and spring (Fig. 1c). During these seasons, the MLD is generally less than $30 \mathrm{~m}$ throughout the SCTR region (Fig. 1e). Surface currents are dominated by the westward South Equatorial Current (SEC) to the south of $10^{\circ} \mathrm{S}$ and the eastward South Equatorial Countercurrent (SECC) between the equator and $5^{\circ} \mathrm{S}$ (Fig. 1e; Schott et al. 2009).

During boreal summer and fall, the pool of highest SSTs is confined to the central and eastern equatorial basin, resulting in a strong northward SST gradient in the SCTR region (Fig. 1b). The southeasterly trade winds strengthen in association with the Indian summer monsoon. The thermocline remains shallow in the SCTR region because of persistent negative wind stress curl and Ekman pumping, though the band of strongest negative wind stress curl has shifted farther north (Fig. 1d). The mixed layer deepens throughout most of the SCTR region during boreal summer. The SEC strengthens in the southern SCTR region in association with enhanced southeasterly trade winds, whereas the eastward flow associated with the SECC disappears and is replaced by southward Ekman currents (Fig. 1f; Schott et al. 2009).

\section{b. Climatological heat balance}

In this section, we analyze the seasonal cycle of the mixed layer heat balance in the SCTR region during 2000-08. We begin by considering the annual mean and seasonal variability of the terms in the heat balance.

The mixed layer heat storage rate is nearly zero averaged during the 2000-08 period, indicating that trends in SST and MLD were very small (Fig. 3a). Seasonal variability of the heat storage rate increases southward within the SCTR region because of the combination of a southward increase in the amplitude of the seasonal cycle of mixed layer temperature and a southward increase in MLD (Figs. 1, 3b).

The mean net surface heat flux $q_{0}$ is positive throughout the SCTR region, reflecting that more heat is gained from solar radiation than is lost through the combination of turbulent heat fluxes and longwave radiation emission 
(Fig. 3c). Seasonal variability of $q_{0}$ increases poleward from the $\sim 7^{\circ}-9^{\circ} \mathrm{S}$ latitude band, reaching a maximum at the southern edge of the SCTR region $\left(12^{\circ} \mathrm{S}\right.$; Fig. $\left.3 \mathrm{~d}\right)$. The stronger variability in the south is primarily due to a stronger seasonal cycle of the solar zenith angle.

Horizontal advection tends to warm the mixed layer throughout the year in the SCTR region because of annual-mean southwestward currents in the presence of a northeastward SST gradient (i.e., SST increases toward the northeast; Fig. 3e). Advection is strongest in terms of both mean and seasonal variability in the southwestern SCTR region, where westward currents are strong and there is a strong seasonal cycle of the zonal SST gradient (Figs. 1, 3e,f). Mean advection is weaker than $q_{0}$ throughout the SCTR region, but its seasonal variability is comparable in magnitude.

The annual-mean warming from the combination of $q_{0}$ and horizontal advection is balanced by cooling from turbulent mixing at the base of the mixed layer $\left(q_{-h}\right.$; Fig. $\left.3 g\right)$. The $q_{-h}$ term reaches a minimum of $\sim-100 \mathrm{~W} \mathrm{~m}^{-2}$ in the southwestern SCTR region, increasing to $\sim-45 \mathrm{~W} \mathrm{~m}^{-2}$ in the northeast. The monthly standard deviation of $q_{-h}$ is generally $10-20 \mathrm{~W} \mathrm{~m}^{-2}$, with a maximum of $40 \mathrm{~W} \mathrm{~m}^{-2}$ in the southwestern portion of the SCTR region (Fig. 3h).

Next, we consider the mixed layer heat balance averaged areally in the SCTR region (Fig. 4). SST reaches a maximum during March-April and then decreases to a minimum of $26^{\circ} \mathrm{C}$ in August. The period of strong cooling during April-July coincides with a minimum in surface and absorbed SWR in June-July. Seasonal variations of LHF and the sum of SHF and LWR are much weaker in comparison to the heat storage rate and SWR terms. The weak seasonal variability of LHF is a consequence of the out-of-phase relationship between surface wind speed and the near-surface vertical humidity gradient $\left(\Delta q=q_{s}-q\right.$, where $q_{s}$ is the saturation specific humidity at the SST and $q$ is the near-surface atmospheric specific humidity): wind speed is at a maximum in boreal summer, when $\Delta q$ is at a minimum. The minimum in $\Delta q$ itself is driven primarily by a corresponding minimum in SST (and hence $q_{s}$ ). In contrast, the seasonal amplitude of $q$ is about half as large as that of $q_{s}$. As a result, seasonal variations of LHF contribute very little to seasonal variations in the net surface heat flux. The net surface heat flux instead is dominated by SWR and varies in phase with the seasonal cycle of mixed layer heat storage rate (Fig. 4c).

Horizontal advection provides a significant source of warming during boreal summer and fall (Fig. 3). Warming from the meridional component is stronger than that from to the zonal component, mainly because of a stronger meridional SST gradient during boreal summer compared
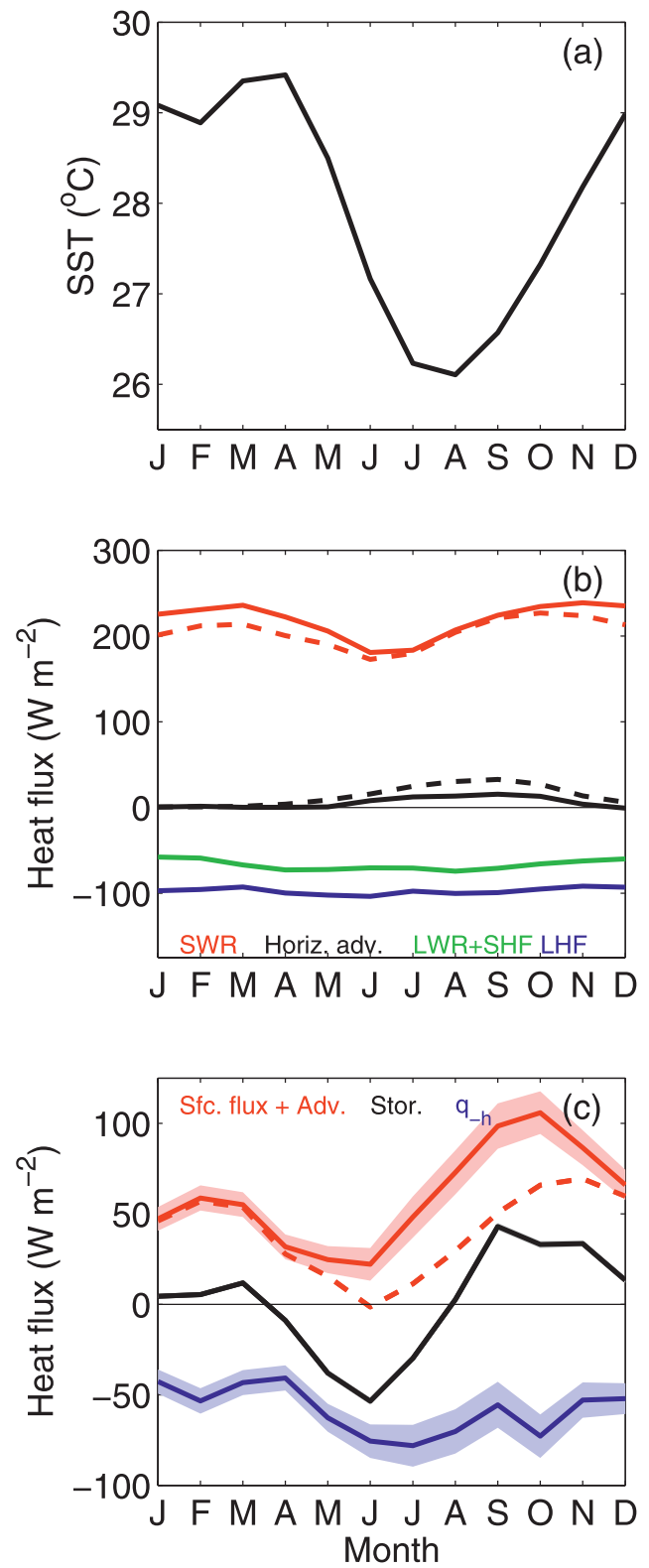

FIG. 4. Area-averaged seasonal cycles in the SCTR region: (a) SST; (b) surface SWR (solid red line), SWR absorbed in the mixed layer (dashed red line), zonal advection (solid black line), meridional advection (dashed black line), the sum of net longwave radiation and sensible heat flux (green line), and latent heat flux (blue line); and (c) the sum of the net surface heat flux and horizontal advection (solid red line), net surface heat flux (dashed red line), mixed layer heat storage rate (black line), and heat balance residual (blue line). Shading in (c) represents one standard error.

to the zonal gradient (Fig. 5). A maximum in MLD during boreal summer also contributes to the maximum in southwestward mixed layer heat advection.

Seasonal variations in the sum of the net surface heat flux and horizontal advection are in phase with those of 

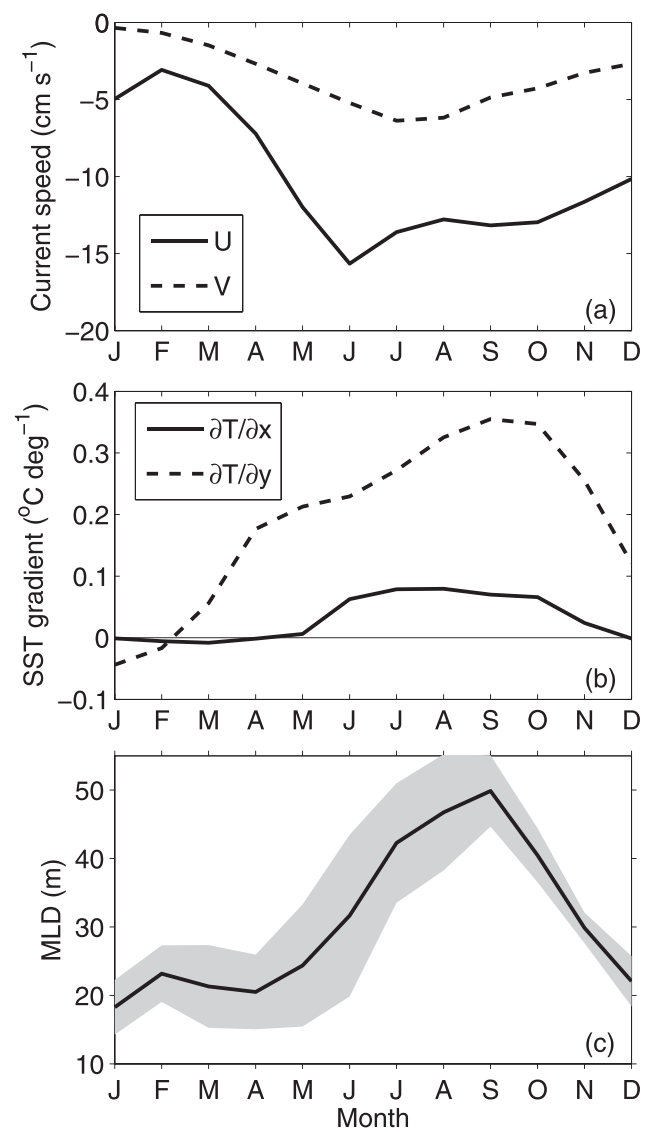

FIG. 5. Area-averaged seasonal cycles in the SCTR region: (a) zonal (solid) and meridional (dashed) OSCAR currents; (b) zonal (solid) and meridional (dashed) SST gradients; and (c) MLD. Shading in (c) indicates one standard error.

the mixed layer heat storage rate. Both terms reach minima in June and maxima in September-October. However, the sum exceeds the storage rate by $40-80 \mathrm{~W} \mathrm{~m}^{-2}$ throughout the year, implying a significant contribution from $q_{-h}$ (Fig. 4c). We expect that the annual-mean $q_{-h}$ can be attributed mainly to cooling resulting from the combination of entrainment and vertical turbulent diffusion. There is also a noticeable seasonal cycle in $q_{-h}$, with a maximum cooling in boreal summer and a minimum in winter. In the next section, we explore the causes of the seasonal cycle of $q_{-h}$ in the SCTR region.

\section{c. Residual}

\section{1) DAtA AND ALGORITHM DEPENDENCE}

It is possible that errors in the terms we estimated contribute significantly to the seasonal cycle of $q_{-h}$. In addition to the random errors discussed in the appendix, there are errors related to mean biases in the parameterizations and datasets we used. In this section, we therefore test the sensitivity of $q_{-h}$ to different pene- trative SWR formulas and surface heat flux, velocity, and MLD products.

We conduct five different sensitivity analyses. For each analysis, we calculate the terms in the mixed layer heat budget using the datasets and methodology described in section 3a, except that we substitute either a different MLD (two different products are used), horizontal velocity, penetrative SWR formula, or surface heat flux. For the MLD sensitivity tests, we use the de Boyer Montégut product, which is based on a $0.03 \mathrm{~kg}$ $\mathrm{m}^{-3}$ density criterion as well as the Coriolis temperature and salinity analyses with a $0.25 \mathrm{~kg} \mathrm{~m}^{-3}$ criterion instead of the original $0.15 \mathrm{~kg} \mathrm{~m}^{-3}$ criterion. The horizontal velocity product is the drifter-based climatology, and the net surface heat flux is the Flux OAFlux $_{\text {product, }}$ which is described in section 2a. For the penetrative SWR sensitivity test, we use the chlorophyll-based algorithm of Ohlmann (2003).

The peak-to-peak seasonal amplitude of $q_{-h}$ varies between 40 and $60 \mathrm{~W} \mathrm{~m}^{-2}$ for each sensitivity test, and the phase is consistent, with maximum cooling in the boreal summer/fall and minimum cooling in winterspring (Fig. 6). The largest uncertainty is associated with the choice of surface heat flux products: the Flux $_{\text {OAFlux }}$ product results in a residual that is larger in magnitude

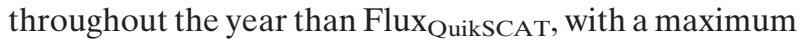
difference of $\sim 25 \mathrm{~W} \mathrm{~m}^{-2}$ in April (black and solid red curves in Fig. 6). However, the seasonality is not significantly changed for different choices of MLD, velocity, and surface flux products. These results suggest that the seasonal cycle of $q_{-h}$ is mainly due to unresolved physical processes and not to uncertainties in the datasets or penetrative SWR algorithm. In the next section, we therefore investigate the physical processes responsible for the seasonal cycle of $q_{-h}$.

\section{2) INTERPRETATION IN TERMS OF PHYSICAL PROCESSES}

The heat balance residual represents the sum of unresolved physical processes and the accumulation of errors from the terms we estimated directly. Among unresolved processes, the most likely candidate is vertical turbulent mixing, which involves turbulent entrainment and diffusion. In this section, we consider only turbulent entrainment, recognizing that turbulent diffusion may also contribute significantly.

We begin by considering qualitatively the onedimensional turbulent energy balance. Entrainment $(\partial h /$ $\partial t>0$ ) occurs when the combination of wind and surface buoyancy forcing results in a net generation of turbulent kinetic energy in the mixed layer (e.g., Kraus and Turner 1967). The amount of energy transferred from the atmosphere to the mixed layer is proportional to the sum 


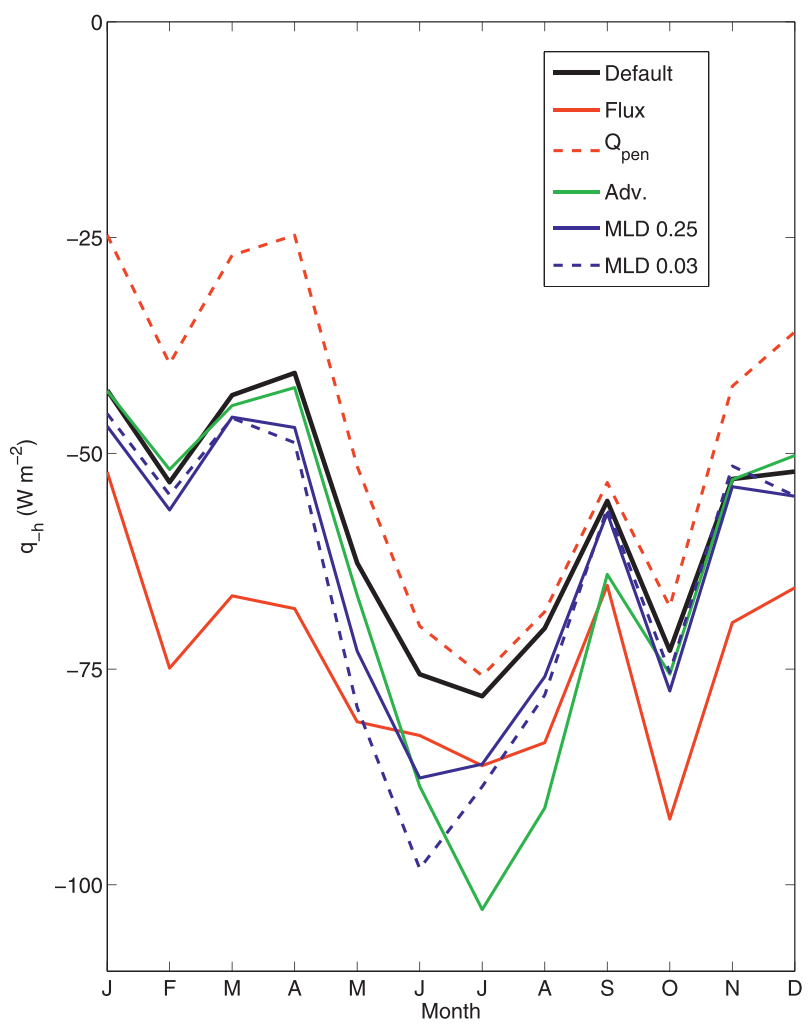

FIG. 6. The $q_{-h}$ term calculated with the default surface heat flux, MLD, velocity, and penetrative radiation terms (solid black line) and with one of these terms replaced with an alternative product (see text for details): surface heat flux (solid red line), penetrative radiation formula (dashed red line), mixed layer horizontal velocity (green line), $0.25 \mathrm{~kg} \mathrm{~m}^{-3}$ criterion for MLD (solid blue line), and de Boyer Montégut MLD with $0.03 \mathrm{~kg} \mathrm{~m}^{-3}$ criterion (dashed blue line).

of the cube of the friction velocity $\left(u_{*}=\sqrt{\tau / \rho}\right.$, where $\tau$ is surface wind stress magnitude and $\rho$ is the density of seawater) and the surface buoyancy flux, defined as $B=$ $B_{h}+B_{w}$, where $B_{h}=\alpha c_{p}^{-1} Q$ is the component due to the surface heat flux and $B_{w}=\beta \rho S(P-E)$ is the component due to the freshwater flux. Here, $\alpha$ is the coefficient of thermal expansion of seawater, $c_{p}$ is the heat capacity, $Q$ is the surface heat flux, and $\beta$ is the coefficient of haline contraction. Evaporation $E$ is calculated as $E=$ $\mathrm{LHF} /\left(\rho L_{e}\right)$, where $L_{e}=2.5-(0.00236 \times \mathrm{SST}) \times 10^{6}$ is the latent heat of vaporization.

The seasonal cycle of $q_{-h}$ agrees reasonably well with the seasonal cycles of $u_{*}^{3}$ and buoyancy forcing (Figs. 7a,b). During boreal winter and spring, the buoyancy flux is positive, wind speed is low, and $q_{-h}$ is relatively weak. During April-June, there is a dramatic increase in $u_{*}^{3}$ as the summer monsoon commences, and there is a concurrent decrease in the surface buoyancy flux that is driven mainly by a decrease in surface SWR (Figs. 4b, $7 b)$. The $q_{-h}$ term decreases from $\sim-40 \mathrm{~W} \mathrm{~m}^{-2}$ in
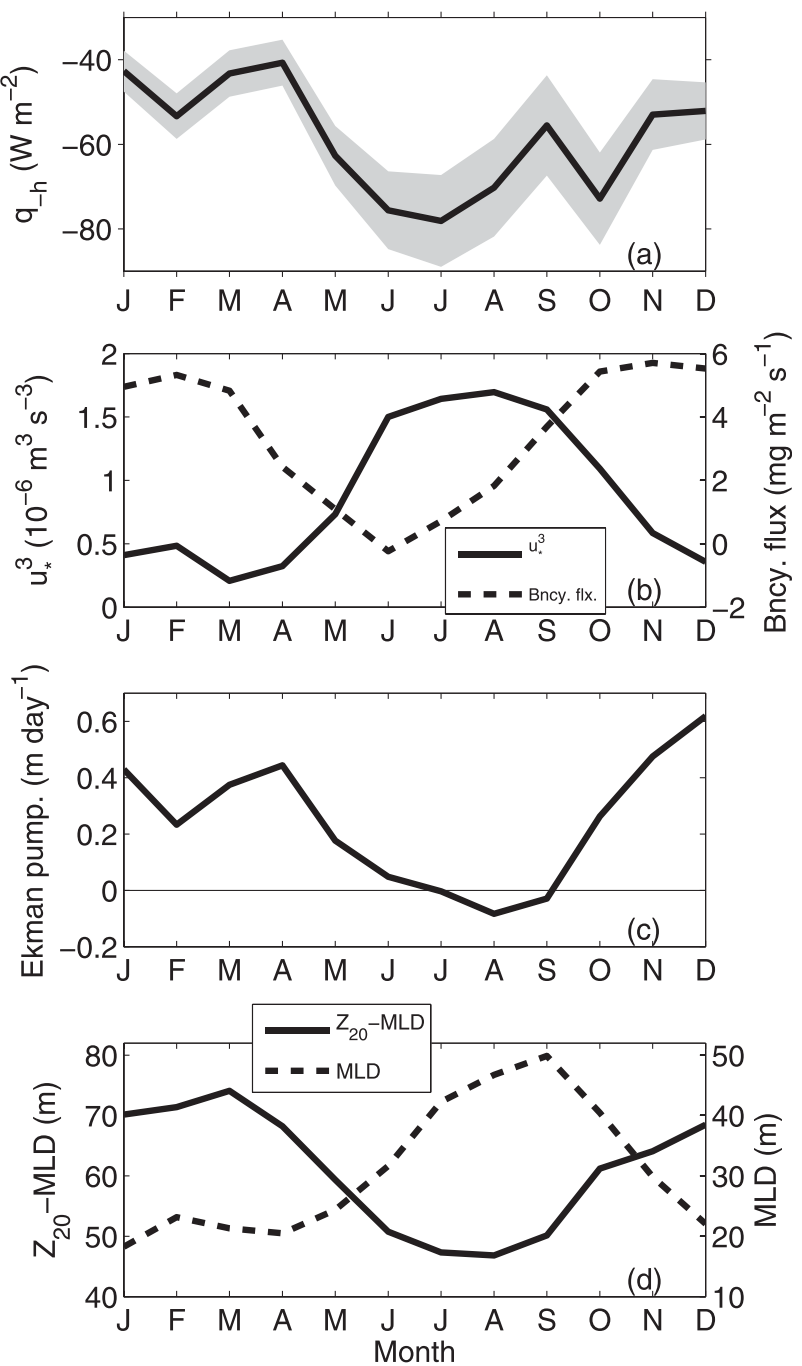

FIG. 7. Area-averaged seasonal cycles in the SCTR region: (a) heat balance residual (shading indicates one standard error); (b) friction velocity cubed (solid) and surface buoyancy flux (dashed); (c) Ekman pumping velocity; (d) the distance between the depth of the $20^{\circ} \mathrm{C}$ isotherm and MLD (solid line) and the MLD (dashed line).

April to $\sim-80 \mathrm{~W} \mathrm{~m}^{-2}$ in July as $u_{*}^{3}$ increases and the buoyancy flux decreases. The mixed layer depth increases from $20 \mathrm{~m}$ in April to $50 \mathrm{~m}$ in September then decreases during the fall as the wind relaxes, suggesting that the $q_{-h}$ term may be dominated by wind-generated turbulent entrainment (Fig. 7d). The increase in MLD coincides with a decrease in the distance between the base of the mixed layer and the top of the thermocline, implying that seasonal variations in the temperature of the entrained water may also contribute significantly. The out-of-phase relationship between $q_{-h}$ and $u_{*}^{3}$ and the in-phase relationship between $q_{-h}$ and buoyancy flux are what would be expected if seasonal changes in $q_{-h}$ were driven by turbulent entrainment. 
It is also possible that seasonal changes in Ekman pumping, $w_{\mathrm{ek}}=\nabla \times(\tau / \rho f)$, may contribute to the seasonal cycle of $q_{-h}$ through their effects on stratification and hence the temperature of entrained water. Ekman pumping in the SCTR region undergoes a distinct semiannual cycle, with maxima in upwelling during April and December, in agreement with the results of Hermes and Reason (2008) and Yokoi et al. (2008). There is also a strong annual cycle, with maximum upwelling during October-May and a minimum during June-September (Fig. 7c). The seasonal variation of $w_{\mathrm{ek}}$ is opposite of what would be expected if Ekman pumping was driving seasonal changes in $q_{-h}$, however, suggesting that Ekman pumping is not a major determinant compared to wind- and buoyancy-forced turbulent mixing.

The qualitative analysis presented in Fig. 7 provides a plausible explanation for the observed maximum magnitude in $q_{-h}$ during boreal summer: an increase in wind speed and decrease in buoyancy flux during boreal spring causes a deepening of the mixed layer and an increase in entrainment cooling. The entrainment cooling is further enhanced during boreal summer because of the seasonal minimum in the distance between the mixed layer and the thermocline. To quantify the entrainment heat flux, we consider the one-dimensional turbulent energy balance of Niiler and Kraus (1977). Entrainment velocity $\left(w_{e} \equiv H \partial h / \partial t\right.$, where $H=0$ for $\partial h / \partial t \leq 0$ and $H=1$ for $\partial h / \partial t>0)$ is diagnosed under the assumption that local turbulence generation is proportional to its dissipation:

$$
w_{e}=\frac{2 m u_{*}^{3}+\frac{h}{2}\left[(1+n) B_{0}-(1-n)\left|B_{0}\right|\right]+\left(h-\frac{2}{\gamma}\right) J_{0}}{c_{i}^{2}-s|\Delta \mathbf{v}|^{2}} .
$$

Here, $u_{*}$ is friction velocity, $h$ is mixed layer depth, $B_{0}$ is surface buoyancy flux, $1 / \gamma$ is the shortwave extinction depth, $J_{0} \equiv\left(g \alpha / \rho c_{p}\right) I_{0}\left(I_{0}\right.$ is the surface shortwave radiation $), c_{i}^{2}=\Delta b h\left[\Delta b=g\left(\rho_{-h}-\rho\right)\right.$ is the buoyancy jump across the base of the mixed layer], and $\Delta \mathbf{v}$ is vertically averaged horizontal mixed layer velocity relative to velocity at the base of the mixed layer. The terms represent, from left to right, turbulence generation due to wind, surface buoyancy flux, and the penetrative component of solar radiation. Each term is scaled by stratification and vertical velocity shear: stronger (weaker) stratification and weaker (stronger) shear tend to reduce (enhance) the magnitude of $w_{e}$. Because we cannot reliably estimate $\Delta \mathbf{v}$ from observations alone, we have used the mean seasonal cycle from SODA (2000-04) repeated for each year.

The constants $m, n$, and $s$ are empirically determined proportionality factors. Niiler and Kraus (1977) suggest that the values of $m$ and $n$ should be similar, whereas Cronin and McPhaden (1997) estimated $m=0.4, n=$ 0.6 , and $s=0.6$ in the western equatorial Pacific and McPhaden (1982) estimated $m=0.4$ at $0^{\circ}, 73^{\circ} \mathrm{E}$. We have therefore assumed $m=0.4$ and $n=s=0.6$. Because of large uncertainty associated with assigning values to the proportionality factors, we expect a high degree of uncertainty in the mean and seasonal amplitude of $w_{e}$ calculated from (2). In agreement with McPhaden (1982), we have found that $w_{e}$ is not significantly affected by the choice of $n$ and $s$. The annual-mean value of $w_{e}$ remains $0.1 \mathrm{~m} \mathrm{day}^{-1}$ for $n=s$ ranging from 0.1 to 1.0 , whereas the peak-to-peak monthly amplitude of $w_{e}$ varies from 0.6 to $0.7 \mathrm{~m} \mathrm{day}^{-1}$ for the same parameter range. In contrast, the choice of $s$ has a much greater influence on $w_{e}$. For $s$ ranging from 0.1 to 0.7 , the annual mean (peak-to-peak monthly amplitude) of $w_{e}$ varies from 0.0 to $0.3 \mathrm{~m} \mathrm{day}^{-1}$ (from 0.2 to $1.2 \mathrm{~m} \mathrm{day}^{-1}$ ). However, the seasonal phase of $w_{e}$ is the same for all reasonable parameter values, with a distinct maximum in June and a broader minimum in boreal winter-spring.

We estimate the entrainment heat flux from (2) as $q_{\mathrm{entr}(\mathrm{NK})}=\rho c_{p} \Delta T w_{e}$. The $\Delta T$ term depends on the vertical temperature gradient below the mixed layer as well as the length scale of turbulent processes as the mixed layer deepens. Values of $0.75^{\circ}-2^{\circ} \mathrm{C}$ have been used in previous studies (i.e., Hayes et al. 1991; McPhaden 1982; Swenson and Hansen 1999; Seager et al. 1988). Here, we set $\Delta T=T-T_{h+10}$, where $T_{h+10}$ is the temperature $10 \mathrm{~m}$ below the base of the mixed layer. This parameterization gives $\Delta T \simeq 1^{\circ}-1.5^{\circ} \mathrm{C}$, which is in the middle of the range used by previous studies.

The seasonal cycle of $q_{\text {entr(NK) }}$ from (2) agrees reasonably well with the seasonal cycle of $q_{-h}$ calculated from the heat balance residual (Fig. 8). Both reach a minimum in boreal summer and a maximum in the winter. There is a sharp decrease in $q_{-h}$ and modeled entrainment during boreal spring that is mainly due to an increase in $u_{*}^{3}$. The combination of the surface buoyancy flux and penetrative radiation opposes wind-induced deepening of the mixed layer for the annual mean, but their seasonal cycles interfere constructively (Fig. 8b). The combined buoyancy-radiation term is strongest in boreal fall, when the surface heat flux is at a maximum and the mixed layer is thick. The temperature jump at the base of the mixed layer $\Delta T$ is strongest in June, when the base of the mixed layer is closest to the top of the thermocline (Figs. 7d, 8b). The covariability of $u_{*}^{3}$ and $\Delta T$ results in an amplification of the seasonal cycle of $q_{\text {entr(NK) }}$. We note that throughout the year the cooling from $q_{\mathrm{entr}(\mathrm{NK})}$ is $\sim 10-50 \mathrm{~W} \mathrm{~m}^{-2}$ weaker than from $q_{-h}$, suggesting that the proportionality factors are too small or that vertical turbulent diffusion is also important. 

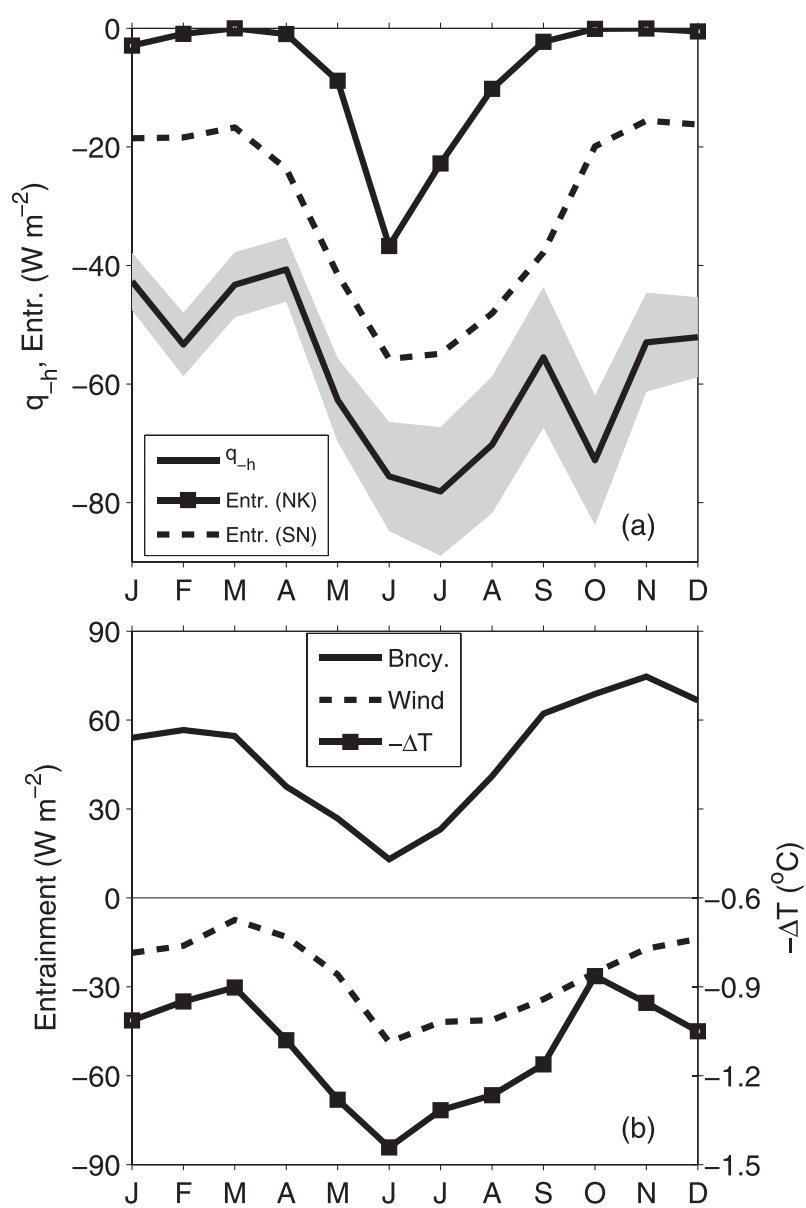

FIG. 8. (a) Heat balance residual $\left[q_{-h}\right.$ in Eq. (1); solid line with shading indicating one standard error], entrainment based on Eq. (2) (solid line with squares), and entrainment based on Eq. (3) (dashed line). (b) Portion of entrainment from Eq. (2) that is due to surface buoyancy flux (solid line) and wind stress (dashed line). Also shown is the temperature jump at the base of the mixed layer ( $\Delta T$; solid line with squares). The sign of $\Delta T$ has been reversed so that larger negative values are associated with stronger entrainment cooling.

An alternative to using (2) is to calculate entrainment using the observed mass balance in the mixed layer. Following Stevenson and Niiler (1983), entrainment velocity can be written

$$
w_{e}=H\left(\frac{\partial h}{\partial t}+\nabla \cdot h \mathbf{v}\right)
$$

Here, we use weekly $h$ and $\mathbf{v}$ and calculate the entrainment heat flux from (3) as $q_{\mathrm{entr}(\mathrm{SN})}=\Delta T w_{e}$. The entrainment heat flux from (3) exhibits a strong seasonal cycle that varies in phase with $q_{-h}$ and $q_{\text {entr(NK) }}$ (Fig. 8). The strong covariability between $q_{-h}$ and two independent estimates of entrainment suggests that the seasonal cycle of $q_{-h}$ is driven primarily by changes in wind-generated turbulent entrainment associated with changes in mixed layer depth.

The magnitude of $q_{-h}$ exceeds the magnitude of both entrainment estimates by $10-60 \mathrm{~W} \mathrm{~m}^{-2}$ throughout the year, suggesting that vertical turbulent diffusion may also contribute significantly (Fig. 8). To test this possibility, we consider the vertical diffusion coefficient, $K_{v}=$ $-q_{\text {diff }} /\left(\rho_{0} c_{p} \partial T / \partial z\right)$, where $q_{\text {diff }}$ is the difference between $q_{-h}$ and the entrainment heat flux, and $\partial T / \partial z$ is the average temperature gradient between the base of the mixed layer and $10 \mathrm{~m}$ below the mixed layer. The annual-mean $K_{v}$ for $q_{\text {entr(NK) }}\left(q_{\text {entr(SN) }}\right)$ is $1.4 \mathrm{~cm}^{2} \mathrm{~s}^{-1}\left(0.7 \mathrm{~cm}^{2} \mathrm{~s}^{-1}\right)$. For both entrainment parameterizations, the climatological monthly-mean values of $K_{v}$ are between 0.4 and $2.5 \mathrm{~cm}^{2} \mathrm{~s}^{-1}$. These values generally agree with the $0.3-$ $2.3 \mathrm{~cm}^{2} \mathrm{~s}^{-1}$ reported by Hayes et al. (1991) for the equatorial Pacific. We note, however, that there are significant differences between the seasonal cycles in the SCTR region and in the eastern equatorial Pacific so that the values of $K_{v}$ in these regions are not expected to match exactly. To estimate an upper bound on $K_{v}$, we assume that the entrainment heat flux is zero and that $q_{-h}$ is entirely due to diffusion. For this case, $K_{v}$ ranges from 0.9 to $2.5 \mathrm{~cm}^{2} \mathrm{~s}^{-1}$. These values are at the upper end of the range reported by Hayes et al. (1991) in the equatorial Pacific, which is not surprising, because Hayes et al. (1991) calculated entrainment separately. The maximum values of $K_{v}$ in the SCTR region are generally less than those calculated by Wang and McPhaden (1999) at $0^{\circ}, 110^{\circ} \mathrm{W}\left(K_{v}=1.8-3.4 \mathrm{~cm}^{2} \mathrm{~s}^{-1}\right)$ and at $0^{\circ}$, $140^{\circ} \mathrm{W}\left(K_{v}=4.0-6.5 \mathrm{~cm}^{2} \mathrm{~s}^{-1}\right)$. However, Wang and McPhaden's (1999) estimates were upper bounds on $K_{v}$ based on the assumption of no entrainment.

\section{d. Heat balance at the $8^{\circ} S, 67^{\circ} \mathrm{E}$ RAMA mooring location}

In sections $4 \mathrm{~b}$ and $4 \mathrm{c}$, we analyzed the mixed layer heat budget in the SCTR region for the 2000-08 period from a combination of satellite and in situ datasets. In this section, we provide a complementary heat budget analysis at the $8^{\circ} \mathrm{S}, 67^{\circ} \mathrm{E}$ RAMA mooring location, which is near the center of the SCTR region (Fig. 1). We focus on the period February 2007 through November 2008 , when measurements from the mooring are available.

SST at the mooring location undergoes a pronounced annual cycle that is in phase with the seasonal cycle of SST in the SCTR region, though the magnitude of the annual cycle of SST is considerably weaker at the mooring location (Fig. 9a). SST has a standard deviation of $0.7^{\circ} \mathrm{C}$ at $8^{\circ} \mathrm{S}, 67^{\circ} \mathrm{E}$ during $2007-08$, compared to $1.0^{\circ} \mathrm{C}$ in the SCTR region. There is also significant interannual variability of SST at the mooring location. For example, 

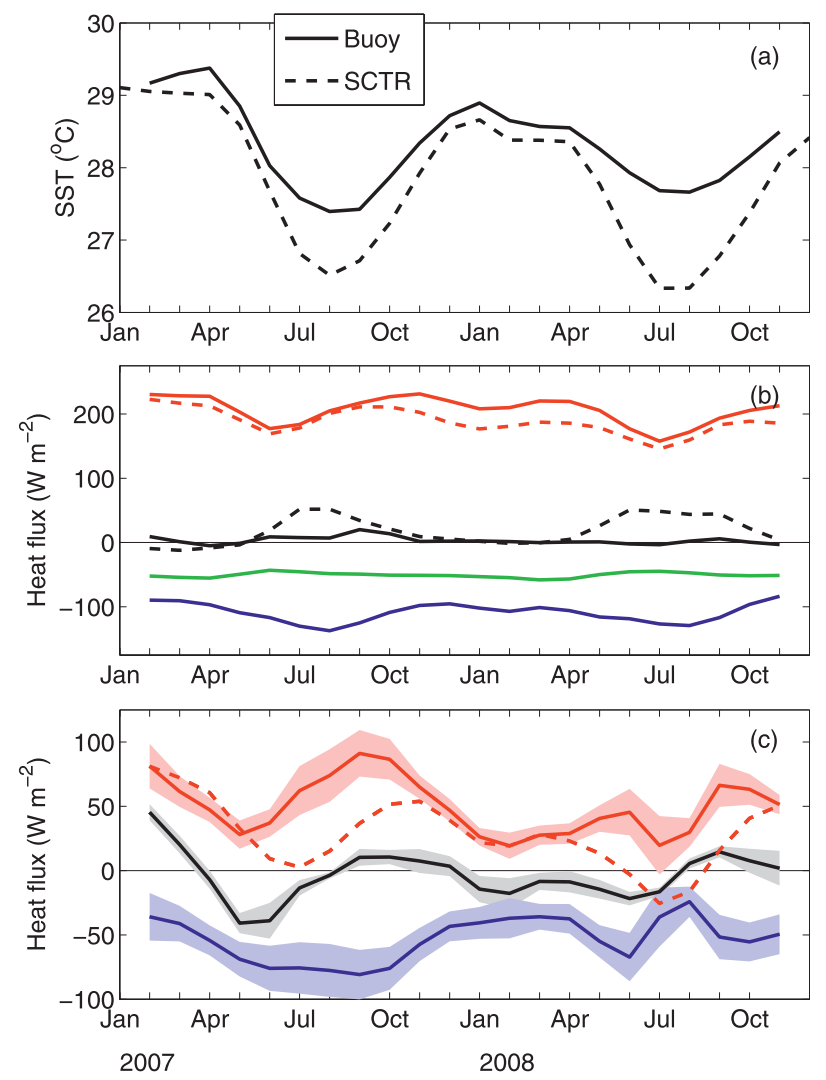

FIG. 9. Monthly SST and mixed layer heat budget at the $8^{\circ} \mathrm{S}, 67^{\circ} \mathrm{E}$ mooring location during February 2007-November 2008: (a) SST (solid black line) and mean seasonal cycle of SST area averaged in the SCTR region; (b) SWR (solid red line), SWR absorbed in the mixed layer (dashed red line), zonal advection (solid black line), meridional advection (dashed black line), the sum of net longwave radiation and sensible heat flux (green line), and latent heat flux (blue line); and (c) the sum of the net surface heat flux and horizontal advection (solid red line), net surface heat flux (dashed red line), mixed layer heat storage rate (black line), and heat balance residual (blue line). Shading in (c) represents one standard error. All time series have been smoothed with a 1-2-1 running mean filter.

SST during February-April 2007 is $0.5^{\circ}-1^{\circ} \mathrm{C}$ warmer than during the same period in 2008 , which is possibly associated with the strong positive Indian Ocean dipole event in 2006 followed by a weaker positive event in 2007 (e.g., Vinayachandran et al. 2007; Behera et al. 2008; Vialard et al. 2009). The SST anomalies during boreal winter 2007 and winter 2008 at the mooring location are consistent with those in the SCTR region during the corresponding time periods (Fig. 9a). In contrast, there are significant differences in SST at the mooring location compared to that in the SCTR region during boreal summer (Fig. 9a). SST at the mooring is warmer in summer 2008 than in summer 2007, whereas SST averaged in the SCTR region is colder during 2008. The causes of these spatial differences in SST are unclear.
Surface SWR and horizontal advection undergo pronounced seasonal cycles at the mooring location (Fig. 9b). Surface and absorbed SWR reach maxima in boreal fall and winter and sharper minima in boreal summer. Horizontal advection provides warming throughout most of the period, with a distinct maximum in boreal summer, when southward Ekman currents and the northward SST gradient are strongest (Figs. 1b,f, 9b). The seasonal cycles of shortwave radiation and horizontal advection at the mooring location are similar to those averaged in the SCTR region (Figs. 4b, 9b). The seasonal amplitude of zonal advection is considerably weaker at the mooring location, however, because of weaker westward surface currents and eastward SST gradients than at other locations in the SCTR region (Figs. 1a,b). The LHF at the mooring location undergoes a strong seasonal cycle, with a minimum (corresponding to strongest latent heat loss) during boreal summer. The stronger seasonal cycle of LHF at the mooring location compared to the SCTR region as a whole is due to a weaker seasonal cycle of the vertical humidity gradient $\left(\Delta q=q_{s}-q\right)$ at the mooring location during 2007-08 compared to the seasonal cycle of $\Delta q$ averaged over the SCTR region during 2000-08 (because $\Delta q$ and wind speed vary out of phase). Additional measurements from RAMA moorings in the southwestern tropical Indian Ocean will help to assess how much of the difference is due to spatial variations of $\Delta q$ versus either biases in NCEP reanalysis $q$ or interannual variability of $q$.

The sum of the net surface flux and horizontal advection varies in phase with changes in the mixed layer heat storage rate during 2007-08 (Fig. 9c). Mixed layer heat content decreases during boreal spring and summer, in association with weaker SWR and stronger latent heat loss, and increases during the fall, when the net surface heat flux reaches a maximum and warming from horizontal advection is strong. The sum of the surface heat flux and horizontal advection exceeds the mixed layer heat storage rate by $\sim 25-75 \mathrm{~W} \mathrm{~m}^{-2}$ throughout the period, suggesting that cooling from vertical turbulent mixing also plays an important role in the annual mean. During 2007, there is a distinct seasonal cycle of $q_{-h}$, with a minimum (i.e., maximum cooling) during boreal summer and fall and a maximum in the winter. The phasing of the annual cycle of $q_{-h}$ in 2007 agrees with the seasonality of $q_{-h}$ in the SCTR region (Fig. 4c). In contrast, during 2008 there is not a clear seasonal cycle of $q_{-h}$ at the mooring location (Fig. 9c).

To investigate the causes of the seasonal cycle of $q_{-h}$ at the mooring location during 2007-08, we calculate the entrainment heat flux from (2) and (3) using buoy surface winds, heat fluxes, MLD, $\Delta \rho$, and $\Delta T$ together with TMI rainfall and OSCAR currents. We have neglected 

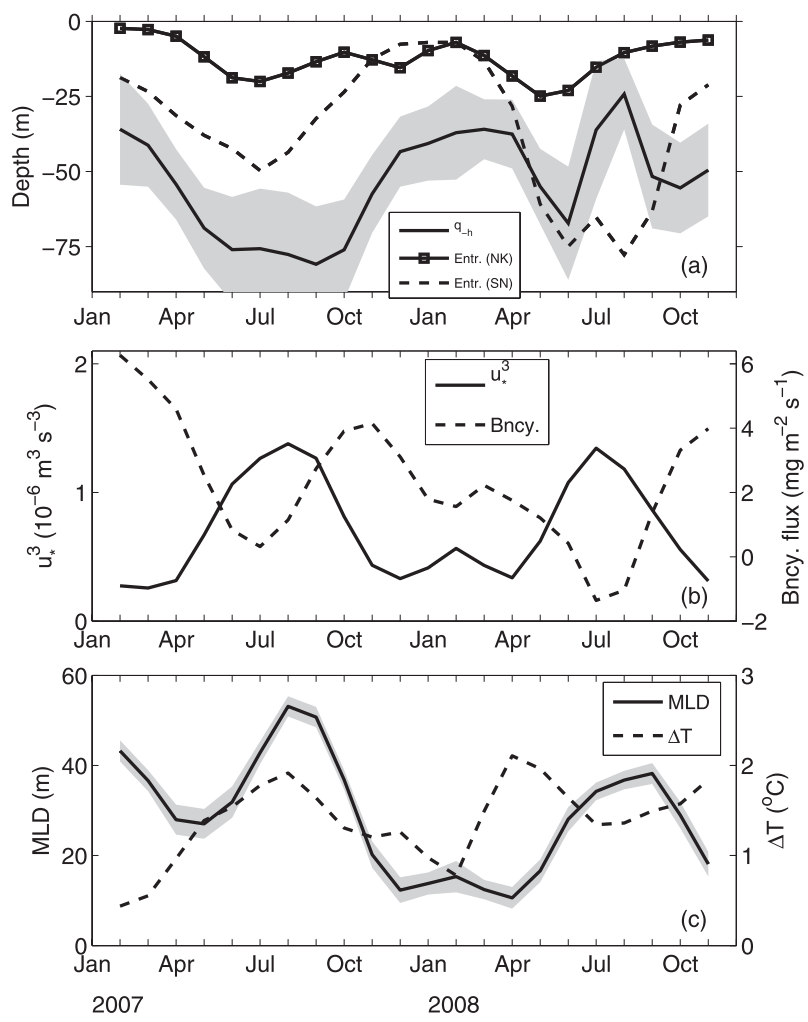

FIG. 10. (a) Heat balance residual $\left[q_{-h}\right.$ in Eq. (1); solid line with shading indicating one standard error], entrainment based on Eq. (2) (solid line with squares), and entrainment based on Eq. (3) (dashed line) at the $8^{\circ} \mathrm{S}, 67^{\circ} \mathrm{E}$ mooring location. (b) Friction velocity cubed (solid line) and surface buoyancy flux (dashed line). (c) MLD (solid line, with shading indicating one standard error) and temperature jump at the base of the mixed layer (dashed line). All time series have been smoothed with a 1-2-1 running mean filter.

the term proportional to $\nabla h$ in (3), because we found that it is insignificant for the mean seasonal cycle compared to $h \boldsymbol{\nabla} \cdot \mathbf{v}$. The modeled $q_{\mathrm{entr( \textrm {NK } )}}$ and $q_{\mathrm{entr( \textrm {SN } )}}$ at the mooring location both reach minima in boreal summer and maxima in the winter, in agreement with the phasing of entrainment in the SCTR region (Figs. 8a, 10a). The $q_{\text {entr(NK) }}$ term at the mooring location is driven primarily by seasonal changes in $u_{*}^{3}$ and the surface buoyancy flux (Fig. 10b). The $u_{*}^{3}$ term varies in phase with MLD, reaching a maximum in boreal summer, whereas the buoyancy flux varies out of phase with $u_{*}^{3}$, which is consistent with the situation in the SCTR region (Figs. $7 \mathrm{~b}, 10 \mathrm{~b}, \mathrm{c})$. The temperature jump at the base of the mixed layer $\Delta T$ also undergoes a noticeable seasonal cycle during 2007 , reaching a maximum in boreal summer, when the mixed layer is thickest (Fig. 10c). The seasonal cycle of $\Delta T$ is more poorly defined during 2008, with a maximum in boreal spring and a local minimum in boreal summer.
The magnitude of the $q_{\text {entr(NK) }}$ term is significantly smaller than that of $q_{-h}$ throughout $2007-08$ at the mooring location, which is consistent with the results for the SCTR region (Figs. 8, 10a). The annual mean and seasonal amplitude of $q_{\mathrm{entr( \textrm {SN } )}}$ are similar to those in the SCTR region (Fig. 10a), with maxima of $50-75 \mathrm{~W} \mathrm{~m}^{-2}$ during boreal summer and minima of $10-25 \mathrm{~W} \mathrm{~m}^{-2}$ during boreal winter. It is possible that the poor vertical resolution of the temperature and salinity sensors on the mooring results in an overestimate of the magnitude of $q_{\text {entr(SN) }}$ during boreal summer 2008. Future measurements from the $8^{\circ} \mathrm{S}, 67^{\circ} \mathrm{E}$ mooring and other RAMA moorings will enable more detailed analyses of the seasonal mixed layer heat budget.

\section{Summary and discussion}

In this study, we examined the seasonal mixed layer heat balance in the Seychelles-Chagos thermocline ridge (SCTR; $50^{\circ}-75^{\circ} \mathrm{E}, 5^{\circ}-12^{\circ} \mathrm{S}$ ) region of the southwestern tropical Indian Ocean. This region is characterized by annual-mean upwelling and strong seasonal cycles of SST and surface winds. It was found that seasonal variations of mixed layer heat content in the SCTR region are driven by a combination of the net surface heat flux, horizontal heat advection, and vertical turbulent mixing at the base of the mixed layer, which is estimated as a residual in the heat balance. The net surface heat flux varies in phase with the mixed layer heat storage rate and reaches a maximum in boreal fall and winter, when surface shortwave radiation is strongest. Horizontal advection is close to zero during boreal winter and spring, when SSTs in the SCTR region are highest and horizontal SST gradients are weak. During boreal summer and fall, surface currents and SST gradients are stronger, resulting in significant warming from horizontal advection. Strong zonal advection is confined mainly to the western SCTR region, where the eastward SST gradient is largest. In contrast, meridional advection is strongest in the eastern SCTR region, where the northward SST gradient is most pronounced. Vertical turbulent mixing at the base of the mixed layer undergoes a significant seasonal cycle. The turbulent mixing term varies out of phase with horizontal advection, tending to cool the mixed layer most strongly during boreal summer. The seasonal mixed layer heat balance in the SCTR region and its relationship to changes in mixed layer depth and thermocline depth are summarized in Fig. 11.

The maximum in turbulent cooling in boreal summer coincides with a maximum in surface wind speed and a minimum in the surface buoyancy flux, suggesting that the seasonal cycle of turbulent cooling is driven primarily by local wind and buoyancy-induced turbulent 


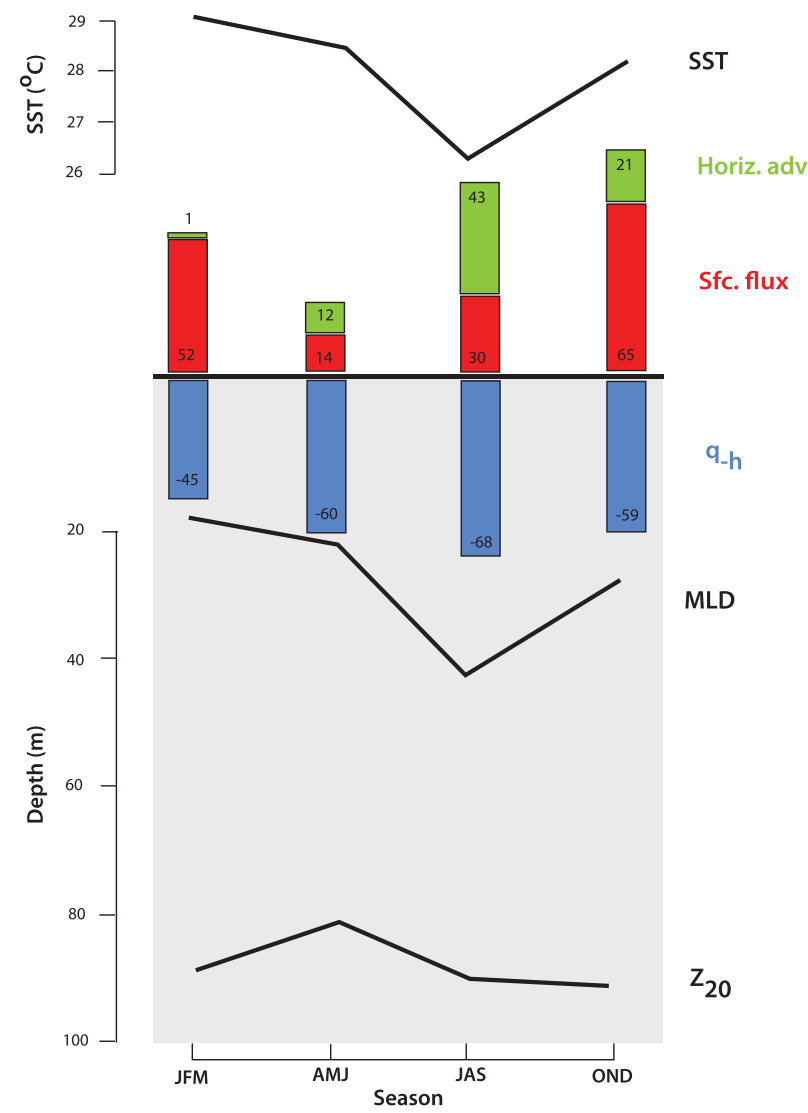

FIG. 11. Processes contributing to the seasonal cycle of SST in the thermocline ridge region. Vertical bars represent seasonal mean values of horizontal mixed layer heat advection (green bars), net surface heat flux (red bars), and the heat balance residual (blue bars) in $\mathrm{W} \mathrm{m}^{-2}$. Positive values indicate heating of the mixed layer. Black lines represent SST, MLD, and depth of the $20^{\circ} \mathrm{C}$ isotherm, with scales on the left.

mixing. Consistent with this interpretation, the observed mixed layer depth increases from $50 \mathrm{~m}$ in May to $80 \mathrm{~m}$ in September. As the mixed layer deepens, the distance between the base of the mixed layer and the top of the thermocline decreases and the temperature gradient at the base of the mixed layer increases, tending to decrease the temperature of water entrained into the mixed layer and enhance the magnitude of the turbulent heat flux. Two independent diagnostic mixed layer models that account for these processes reproduce the observed seasonal cycle of turbulent cooling in the SCTR region. The processes responsible for the seasonal cycle of entrainment heat flux are shown schematically in Fig. 12.

The mixed layer heat balance at a RAMA mooring located near the center of the SCTR region $\left(8^{\circ} \mathrm{S}, 67^{\circ} \mathrm{E}\right)$ is generally consistent with the climatological heat balance averaged in the SCTR region. The net surface heat flux, horizontal advection, and vertical turbulent mixing all contribute significantly to the seasonal cycle of mixed layer heat storage during 2007-08. During 2007, the turbulent cooling term is strongest in boreal summer, when the surface wind speed is highest and mixed layer is deepening, as for the climatological heat balance in the SCTR region. In contrast, during 2008 turbulent cooling was weaker, without a clear seasonal cycle. We found that the net surface heat flux tended to heat the mixed layer more during boreal summer and fall 2007 than during the same time period in 2008 , which is consistent with the development of a positive Indian Ocean dipole event during the summer of 2007 (Vinayachandran et al. 2007; Behera et al. 2008; Vialard et al. 2009).

Our empirical results for the SCTR region agree well with the modeling study of Zhou et al. (2008) in the eastern SCTR region $\left(6^{\circ}-7^{\circ} \mathrm{S}, 63^{\circ}-73^{\circ} \mathrm{E}\right)$. They also show that strong warming from horizontal advection in boreal summer is balanced by entrainment cooling so that the seasonal cycle of SST is driven mainly by the surface heat flux. In contrast, the modeling results of Hermes and Reason (2008) and Yokoi et al. (2008) suggest that seasonal variations of Ekman pumping contribute significantly to the seasonal cycle of upper-ocean heat content in the SCTR region. The differences are likely due to the fact that Hermes and Reason (2008) and Yokoi et al. (2008) considered the heat balance down to a fixed isotherm and depth, respectively, whereas Zhou et al. (2008) and our analysis considered the heat balance in the mixed layer. Analyzing the heat balance in the mixed layer is advantageous, because it allows for a direct diagnosis of SST variability.

SST in the SCTR region plays an important role in the climate of the Indian Ocean sector through its effects on atmospheric circulation and moisture transport. Understanding the seasonal cycle of SST is an important step toward a more complete understanding of oceanatmosphere interactions in the tropical Indian Ocean and their effects on the Indian summer monsoon. The results from this study will be useful as a basis for future studies of intraseasonal and interannual SST variability in the SCTR region and to validate numerical model simulations.

Acknowledgments. We thank Fabienne Gaillard for providing us the Coriolis objective analysis and Clément de Boyer Montégut for making his interannual mixed layer product available to us. We are grateful to Rick Lumpkin for providing the drifter climatology and to Lisan Yu for providing the OAFlux data. We would also like to acknowledge three anonymous reviewers, whose comments greatly improved the final manuscript. TMI/ AMSR-E data are produced by Remote Sensing Systems (available online at http://www.remss.com). GRF and MJM are funded by the NOAA Climate Program 


\section{$\underline{\text { June - August }}$}

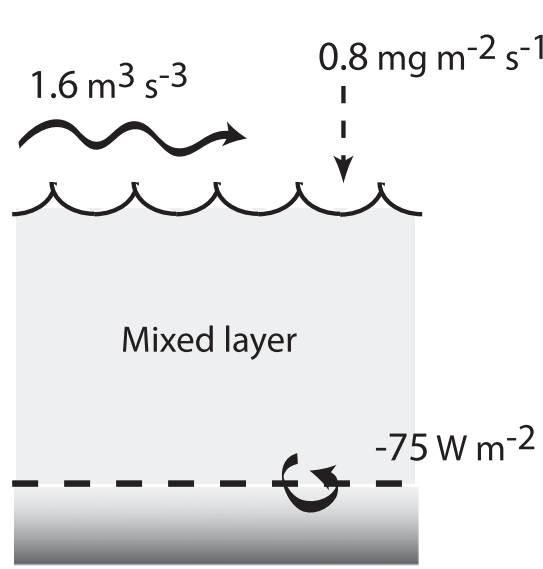

Thermocline
January-March

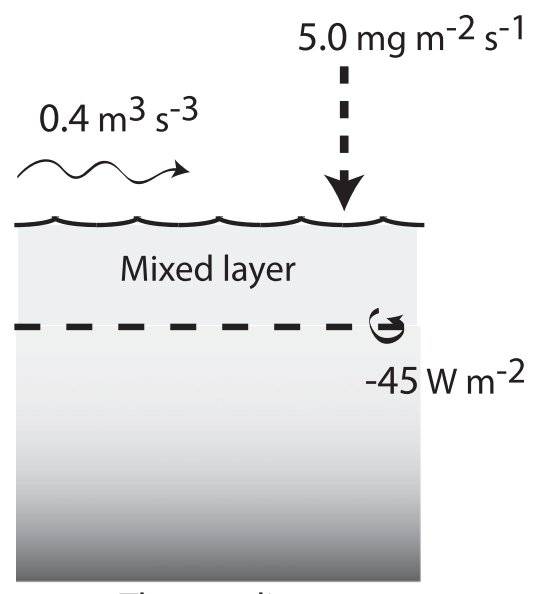

Thermocline

FIG. 12. Schematic diagram illustrating the processes responsible for the seasonal cycle of entrainment in the SCTR region. The numbers are averages of friction velocity cubed (wavy solid lines), buoyancy flux (dashed vertical lines), and the heat balance residual $\left(q_{-h}\right.$; circular arrows) during the three-month periods indicated. These periods were chosen to give the maximum seasonal range of the entrainment heat flux. Positive values of buoyancy flux and $q_{-h}$ indicate a flux into the mixed layer. Horizontal dashed line represents the MLD.

Office. JV is funded by Institut de Recherche pour le Développement (IRD) and did this work while visiting National Institute of Oceanography (NIO, India). BPK is supported by a Counsil of Scientific and Industrial Research (CSIR, India) fellowship.

\section{APPENDIX}

\section{Error Estimates}

Here, we describe the methodology used to estimate errors for each term in the mixed layer heat balance equation for the satellite-Argo analysis averaged in the SCTR region and for the analysis at the RAMA mooring location.

\section{a. Satellite-Argo}

Uncertainties in MLD result primarily from sampling errors associated with Argo profiles in the SCTR region. These errors are estimated for each calendar month as the RMS difference between the monthly-mean Coriolis MLD product and the de Boyer Montégut product, which uses a different MLD criterion and analysis method. Errors range from $\pm 2 \mathrm{~m}$ in November to $\pm 12 \mathrm{~m}$ in June.

Errors in horizontal mixed layer heat advection are calculated using errors in OSCAR currents ( 7 and $6 \mathrm{~cm} \mathrm{~s}^{-1}$ for the zonal and meridional components, re- spectively, based on 5-day-averaged RMS differences between buoy measurements) and TMI SST $\left(0.2^{\circ} \mathrm{C} \mathrm{RMS}\right.$ difference between daily buoy measurements). Seasonal variations in the magnitude of the errors follow the seasonal cycle of advection, with monthly errors in both advection components typically $10-20 \mathrm{~W} \mathrm{~m}^{-2}$ during boreal winter and 40-50 $\mathrm{W} \mathrm{m}^{-2}$ during boreal summer.

Errors in the surface flux terms were assessed as the monthly RMS differences with values calculated from measurements at the $8^{\circ} \mathrm{S}, 67^{\circ} \mathrm{E}$ mooring location during 2007-08 (16, 12, 2, and $2 \mathrm{~W} \mathrm{~m}^{-2}$ for SWR, LHF, LWR, and SHF, respectively). These error estimates likely represent an upper bound, because the satellite-based fluxes are averaged over $\mathrm{a} \sim 2^{\circ} \times 2^{\circ}$ area and the mooring data are point measurements, and there are errors in the mooring measurements. Errors in penetrative SWR are calculated using errors in MLD and SWR. Errors in $q_{-h}$ are calculated as the sum of the errors for the other terms in (1), assuming the individual errors are uncorrelated in time.

We average each term in (1) to a monthly climatology, thereby reducing errors by $67 \%$, assuming 9 independent monthly values for each calendar month at each grid point (2000-08). To calculate errors for quantities averaged in the SCTR region we first estimate the spatial degrees of freedom (DOF) following Smith et al. (1994). We find that there are generally $\sim 2-4$ DOF for each term in the SCTR region. For simplicity, we therefore assume 3 DOF for 
all terms. Errors for area-averaged quantities are then calculated as $\epsilon_{\text {ave }}=\sqrt{[1 / N(\text { dof })] \sum_{i=1}^{N} \epsilon_{i}^{2}}$, where $N$ is the number of grid points and $\epsilon_{i}$ is the error for each grid point. Averaging spatially therefore reduces errors by $\sim 40 \%$. Thus, averaging to an area-averaged monthly climatology reduces random errors by $\sim 80 \%$ compared to individual monthly values for $2000-08$ at a single grid point. Table A1 shows typical errors for monthly-mean climatologies of each term in the heat balance Eq. (1).

\section{b. RAMA mooring}

One of the main sources of error in the heat budget analysis at the mooring location is the estimation of MLD from the coarse vertical spacing of the buoy temperature and salinity measurements. We estimate these errors using 101 CTD profiles from World Ocean Database 2001 (WOD01; Conkright et al. 2002) in the region $50^{\circ}-90^{\circ} \mathrm{E}, 0^{\circ}-20^{\circ} \mathrm{S}$ following the methodology of Foltz and McPhaden (2009). We found typical errors in daily averaged MLD of $\pm 9 \mathrm{~m}$. Daily errors in mixed layer heat storage rate resulting from errors in MLD are $27 \mathrm{~W} \mathrm{~m}^{-2}$ on average. Errors in mixed layer temperature are negligible compared to errors in MLD resulting from the vertical homogeneity of temperature in the mixed layer.

Errors in horizontal heat advection are calculated using errors in MLD combined with errors in horizontal currents and TMI SST. We assume an error in TMI SST of $0.2^{\circ} \mathrm{C}$ based on the daily RMS difference with buoy SST. Sampling error for buoy currents is $\pm 5 \mathrm{~cm} \mathrm{~s}^{-1}$ (Freitag et al. 2003). There is also error because of differences between velocity measured at $10 \mathrm{~m}$ at the mooring and the actual vertically averaged mixed layer velocity. Using monthly data from SODA for 2000-04, we found an RMS difference of $3 \mathrm{~cm} \mathrm{~s}^{-1}\left(2 \mathrm{~cm} \mathrm{~s}^{-1}\right)$ between $10 \mathrm{~m}$ and mixed layer zonal (meridional) velocity. We have therefore added these errors to the instrumental errors before computing horizontal advection errors. Mean daily errors in zonal (meridional) advection are $\pm 29 \mathrm{~W} \mathrm{~m}^{-2}\left( \pm 36 \mathrm{~W} \mathrm{~m}^{-2}\right)$, with the largest errors (up to $\pm 100 \mathrm{~W} \mathrm{~m}^{-2}$ ) during boreal summer.

Errors in the daily averaged surface turbulent heat flux terms are calculated using instrumental errors for air temperature, SST, wind speed, and relative humidity $\left(0.2^{\circ} \mathrm{C}, 0.02^{\circ} \mathrm{C}, 0.3 \mathrm{~m} \mathrm{~s}^{-1}\right.$, and $2.7 \%$, respectively), together with uncertainties associated with the estimation of LHF and SHF from bulk algorithms ( 12\%; Fairall et al. 1996). Instrumental errors lead to uncertainties in daily LHF and SHF at each mooring location of $\sim \pm 15$ and $\sim \pm 2 \mathrm{~W} \mathrm{~m}^{-2}$, respectively. Errors associated with the bulk algorithms give uncertainties in LHF and SHF of $\sim \pm 15$ and $\sim \pm 1 \mathrm{~W} \mathrm{~m}^{-2}$, respectively. Total errors in daily LHF and SHF are $\sim \pm 20$ and $\sim \pm 3 \mathrm{~W} \mathrm{~m}^{-2}$, re-
TABLE A1. Typical monthly-mean errors (left) for the climatological satellite-Argo analysis averaged in the SCTR region and (right) for the analysis at the $8^{\circ} \mathrm{S}, 67^{\circ} \mathrm{E}$ RAMA mooring location. Units are in $\mathrm{W} \mathrm{m}^{-2}$.

\begin{tabular}{lcc}
\hline \hline & Satellite & RAMA \\
\hline Surface flux & 4 & 9 \\
Horizontal advection & 7 & 15 \\
Heat storage & 2 & 12 \\
Residual & 8 & 23 \\
\hline
\end{tabular}

spectively, where we have assumed that instrumental and bulk algorithm errors are uncorrelated in time.

Errors in daily averaged LWR are the combination of instrumental errors $( \pm 1 \%)$ and errors in the LWR bulk flux algorithm. We estimate errors in the bulk algorithm as the daily RMS difference between our estimates of LWR, based on buoy measurements and the Clark et al. (1974) bulk algorithm, and direct measurements from the mooring during January-February 2007. We found an RMS difference of $6 \mathrm{~W} \mathrm{~m} \mathrm{~m}^{-2}$. Errors in absorbed SWR result from instrumental errors in surface SWR $( \pm 2 \%$; Cronin and McPhaden 1997) and sampling errors in $h$. Total daily errors in absorbed SWR are $\sim \pm 14 \mathrm{~W} \mathrm{~m}^{-2}$.

To calculate errors for monthly averages of each parameter, we first calculate the integral time scale (an estimate of the time period required to gain a new degree of freedom) for each month following Davis (1976). We found values of 2-3 days for each parameter averaged over the length of each data record. For simplicity, we therefore use a value of 3 days in all calculations, giving $\sim 10$ degrees of freedom for each month. Averaging to monthly means therefore reduces random errors in daily data by a factor of about 3 . Table A1 shows typical monthly-mean errors for each term in the heat balance Eq. (1).

\section{REFERENCES}

Annamalai, H., P. Liu, and S.-P. Xie, 2005: Southwest Indian Ocean SST variability: Its local effect and remote influence on Asian monsoons. J. Climate, 18, 4150-4167.

- H. Okajima, and M. Watanabe, 2007: Possible impact of the Indian Ocean SST on the Northern Hemisphere circulation during El Niño. J. Climate, 20, 3164-3189.

Behera, S. K., J.-J. Luo, and T. Yamagata, 2008: Unusual IOD event of 2007. Geophys. Res. Lett., 35, L14S11, doi:10.1029/ 2008GL034122.

Black, E., J. Slingo, and K. R. Sperber, 2003: An observational study of the relationship between excessively strong short rains in coastal East Africa and Indian Ocean SST. Mon. Wea. Rev., 131, 74-94.

Bonjean, F., and G. S. E. Lagerloef, 2002: Diagnostic model and analysis of the surface currents in the tropical Pacific Ocean. J. Phys. Oceanogr., 32, 2938-2954. 
Carton, J. A., X. Cao, G. Chepurin, and B. S. Giese, 2000: A Simple Ocean Data Assimilation retrospective analysis of the global ocean 1950-1995. J. Phys. Oceanogr., 30, 294-309.

Clark, N. E., L. Eber, R. M. Laurs, J. A. Renner, and J. F. T. Saur, 1974: Heat exchange between ocean and atmosphere in the eastern North Pacific for 1961-71. NOAA Tech. Rep. NMRS SSRF-682, 108 pp.

Conkright, M. E., and Coauthors, 2002: Introduction. Vol. 1, World Ocean Database 2001, NOAA Atlas NESDIS 42, 167 pp.

Cronin, M. F., and M. J. McPhaden, 1997: The upper ocean heat balance in the western equatorial Pacific warm pool during September-December 1992. J. Geophys. Res., 102, 85338553.

Davis, R. E., 1976: Predictability of sea surface temperatures and sea level pressure anomalies over the North Pacific Ocean. J. Phys. Oceanogr., 6, 249-266.

de Boyer Montégut, C., G. Madec, A. S. Fischer, A. Lazar, and D. Iudicone, 2004: Mixed layer depth over the global ocean: An examination of profile data and a profile-based climatology. J. Geophys. Res., 109, C12003, doi:10.1029/2004JC002378.

Duvel, J.-P., and J. Vialard, 2007: Indo-Pacific sea surface temperature perturbations associated with intraseasonal oscillations of the tropical convection. J. Climate, 20, 3056-3082.

Fairall, C. W., E. F. Bradley, D. P. Rogers, J. B. Edson, and G. S. Young, 1996: Bulk parameterization of air-sea fluxes for Tropical Ocean-Global Atmosphere Coupled Ocean-Atmosphere Response Experiment. J. Geophys. Res., 101, 3747-3764.

$\longrightarrow,-$ J. E. Hare, A. A. Grachev, and J. B. Edson, 2003: Bulk parameterization of air-sea fluxes: Updates and verification for the COARE algorithm. J. Climate, 16, 571-591.

Foltz, G. R., and M. J. McPhaden, 2005: Mixed layer heat balance on intraseasonal time scales in the northwestern tropical Atlantic Ocean. J. Climate, 18, 4168-4184.

$\longrightarrow$, and — 2009: Impact of barrier layer thickness on SST in the central tropical North Atlantic. J. Climate, 22, 285-299.

Freitag, H. P., M. J. McPhaden, C. Meinig, and P. Plimpton, 2003: Mooring motion bias of point Doppler current meter measurements. Proc. Seventh Working Conf. on Current Measurement Technology, San Diego, CA, IEEE, 155-160.

Gaillard, F., E. Autret, V. Thierry, P. Galaup, C. Coatanoan, and T. Loubrieu, 2009: Quality control of large Argo datasets. J. Atmos. Oceanic Technol., 26, 337-351.

Goddard, L., and N. E. Graham, 1999: Importance of the Indian Ocean for simulating rainfall anomalies over eastern and southern Africa. J. Geophys. Res., 104, 19 099-19 116.

Han, W., D. Yuan, W. T. Liu, and D. J. Halkides, 2007: Intraseasonal variability of Indian Ocean sea surface temperature during boreal winter: Madden-Julian Oscillation versus submonthly forcing and processes. J. Geophys. Res., 112, C04001, doi:10.1029/2006JC003791.

Hayes, S. P., P. Chang, and M. J. McPhaden, 1991: Variability of the sea surface temperature in the eastern equatorial Pacific during 1986-88. J. Geophys. Res., 96, 10 553-10 566.

Hermes, J. C., and C. J. C. Reason, 2008: Annual cycle of the South Indian Ocean (Seychelles-Chagos) thermocline ridge in a regional ocean model. J. Geophys. Res., 113, C04035, doi:10.1029/ 2007JC004363.

Izumo, T., C. D. Montégut, J. J. Luo, S. K. Behera, S. Masson, and T. Yamagata, 2008: The role of the western Arabian Sea upwelling in Indian monsoon rainfall variability. J. Climate, 21, 5603-5623

Joseph, P. V., J. K. Eischeid, and R. J. Pyle, 1994: Interannual variability of the onset of the Indian summer monsoon and its association with atmospheric features, El Niño, and sea surface temperature anomalies. J. Climate, 7, 81-105.

Kalnay, E., and Coauthors, 1996: The NCEP/NCAR 40-Year Reanalysis Project. Bull. Amer. Meteor. Soc., 77, 437-471.

Kanamitsu, M., W. Ebisuzaki, J. Woollen, S. K. Yang, J. J. Hnilo, M. Fiorino, and G. L. Potter, 2002: NCEP-DOE AMIP-II reanalysis (R-2). Bull. Amer. Meteor. Soc., 83, 1631-1643.

Kraus, E. B., and J. S. Turner, 1967: A one-dimensional model of the seasonal thermocline. II. The general theory and its consequences. Tellus, 19, 98-105.

Liebmann, B., and C. A. Smith, 1996: Description of a complete (interpolated) outgoing longwave radiation dataset. Bull. Amer. Meteor. Soc., 77, 1275-1277.

Lumpkin, R., and S. L. Garzoli, 2005: Near-surface circulation in the tropical Atlantic Ocean. Deep-Sea Res. I, 52, 495-518.

McPhaden, M. J., 1982: Variability in the central equatorial Indian Ocean. Part II: Oceanic heat and turbulent energy balance. J. Mar. Res., 40, 403-419.

— , and Coauthors, 2009: RAMA: The Research Moored Array for African-Asian-Australian Monsoon Analysis and Prediction. Bull. Amer. Meteor. Soc., 90, 459-480.

Moisan, J. R., and P. P. Niiler, 1998: The seasonal heat budget of the North Pacific: Net heat flux and heat storage rates (19501990). J. Phys. Oceanogr., 28, 401-421.

Morel, A., and D. Antoine, 1994: Heating rate within the upper ocean in relation to its bio-optical state. J. Phys. Oceanogr., 24, 1652-1665.

Murtugudde, R., and A. J. Busalacchi, 1999: Interannual variability of the dynamics and thermodynamics of the tropical Indian Ocean. J. Climate, 12, 2300-2326.

Niiler, P. P., and E. B. Kraus, 1977: One-dimensional models of the upper ocean. Modelling and Prediction of the Upper Layers of the Ocean, E. B. Kraus, Ed., Pergamon, 143-172.

Ohlmann, J. C., 2003: Ocean radiant heating in climate models. J. Climate, 16, 1337-1351.

Saji, N. H., S.-P. Xie, and C.-Y. Tam, 2006: Satellite observations of intense intraseasonal cooling events in the tropical south Indian Ocean. Geophys. Res. Lett., 33, L14704, doi:10.1029/ 2006GL026525.

Schott, F. A., S.-P. Xie, and J. P. McCreary Jr., 2009: Indian Ocean circulation and climate variability. Rev. Geophys., 47, RG1002, doi:10.1029/2007RG000245.

Seager, R., S. E. Zebiak, and M. A. Cane, 1988: A model of the tropical Pacific sea surface temperature climatology. J. Geophys. Res., 93, 1266-1280.

Smith, T. M., R. W. Reynolds, and C. F. Ropelewski, 1994: Optimal averaging of seasonal sea surface temperatures and associated confidence intervals (1860-1989). J. Climate, 7, 949-964.

Stevenson, J. W., and P. P. Niiler, 1983: Upper ocean heat budget during the Hawaii-to-Tahiti Shuttle Experiment. J. Phys. Oceanogr., 13, 1894-1907.

Sweeney, C., A. Gnanadesikan, S. M. Griffies, M. J. Harrison, A. J. Rosati, and B. L. Samuels, 2005: Impacts of shortwave penetration depth on large-scale ocean circulation and heat transport. J. Phys. Oceanogr., 35, 1103-1119.

Swenson, M. S., and D. V. Hansen, 1999: Tropical Pacific Ocean mixed layer heat budget: The Pacific cold tongue. J. Phys. Oceanogr., 29, 69-81.

Ummenhofer, C. C., A. Sen Gupta, M. H. England, and C. J. C. Reason, 2009: Contributions of Indian Ocean sea surface temperatures to enhanced East African rainfall. J. Climate, 22, 993-1013. 
Vecchi, G. A., and D. E. Harrison, 2001: January 1999 Indian Ocean cooling event. Geophys. Res. Lett., 28, 3717-3720.

$\longrightarrow$, and - 2004: Interannual Indian rainfall variability and Indian Ocean sea surface temperature anomalies. Earth's Climate: The Ocean-Atmosphere Interaction, Geophys. Monogr., Vol. 147, Amer. Geophys. Union, 247-260.

Vialard, J., G. R. Foltz, M. J. McPhaden, J. P. Duvel, and C. de Boyer Montégut, 2008: Strong Indian Ocean sea surface temperature signals associated with the Madden-Julian Oscillation in late 2007 and early 2008. Geophys. Res. Lett., 35, L19608, doi:10.1029/2008GL035238.

_ , and Coauthors, 2009: Cirene: Air-sea interactions in the Seychelles-Chagos thermocline ridge region. Bull. Amer. Meteor. Soc., 90, 45-61.

Vinayachandran, P. N., and N. H. Saji, 2008: Mechanisms of South Indian Ocean intraseasonal cooling. Geophys. Res. Lett., 35, L23607, doi:10.1029/2008GL035733.

_ J. Kurian, and C. P. Neema, 2007: Indian Ocean response to anomalous conditions in 2006. Geophys. Res. Lett., 34, L15602, doi:10.1029/2007GL030194.
Wang, W., and M. J. McPhaden, 1999: The surface-layer heat balance in the equatorial Pacific Ocean. Part I: Mean seasonal cycle. J. Phys. Oceanogr., 29, 1812-1831.

Xie, S.-P., H. Annamalai, F. A. Schott, and J. P. McCreary, 2002: Structure and mechanisms of south Indian Ocean climate variability. J. Climate, 15, 864-878.

Yokoi, T., T. Tozuka, and T. Yamagata, 2008: Seasonal variation of the Seychelles Dome. J. Climate, 21, 3740-3754.

Yu, L. S., and R. A. Weller, 2007: Objectively analyzed air-sea heat fluxes for the global ice-free oceans (1981-2005). Bull. Amer. Meteor. Soc., 88, 527-539.

Zhang, Y., W. B. Rossow, A. A. Lacis, V. Oinas, and M. I. Mishchenko, 2004: Calculation of radiative fluxes from the surface to top of atmosphere based on ISCCP and other global data sets: Refinements of the radiative transfer model and the input data. J. Geophys. Res., 109, D19105, doi:10.1029/ 2003JD004457.

Zhou, L., R. Murtugudde, and M. Jochum, 2008: Seasonal influence of Indonesian Throughflow in the southwestern Indian Ocean. J. Phys. Oceanogr., 38, 1529-1541. 